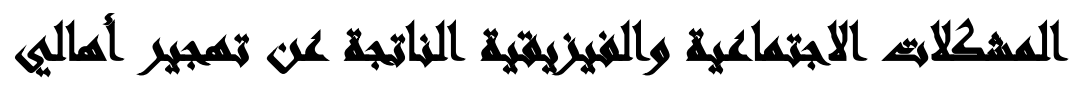

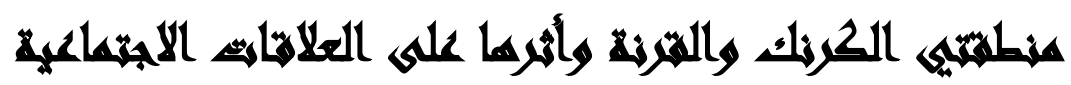 تواسمة مئمانهي
}

[1.]

منى السيد حافظ عبد الرحمن(')- أحمد عبد الحميد الفقى محمد(')- فاطمة محمد الطاهر ( ) كلية الآداب، جامعة عين شئ الردس

\section{المستخليس}

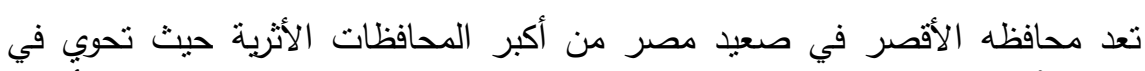

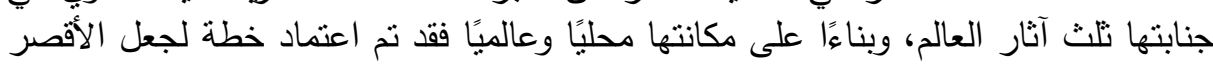

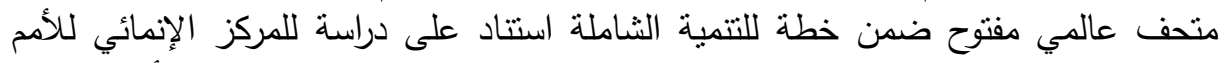

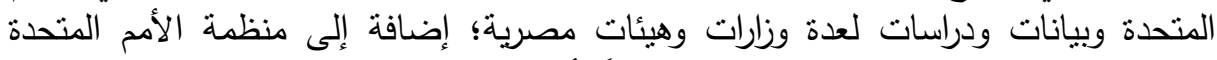

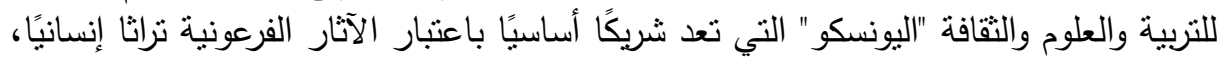

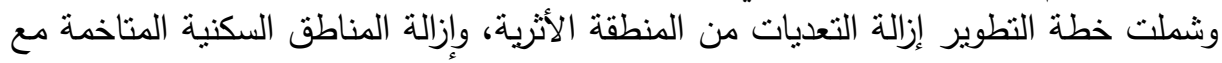

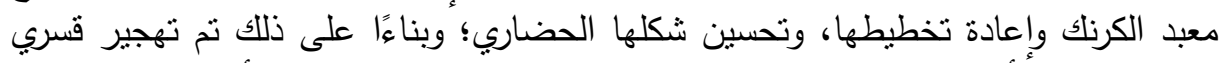

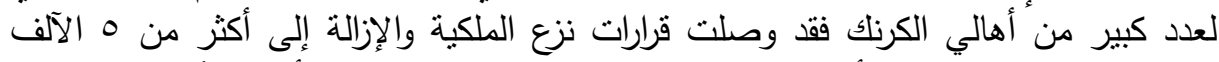

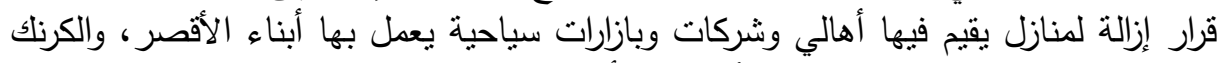

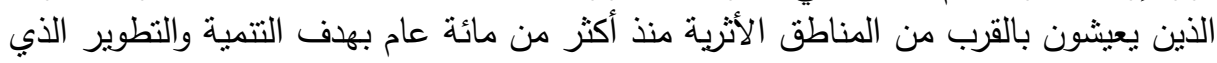

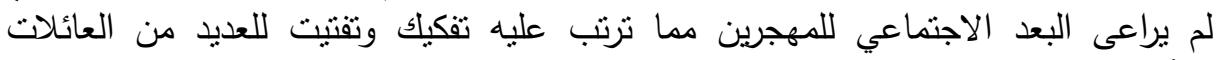

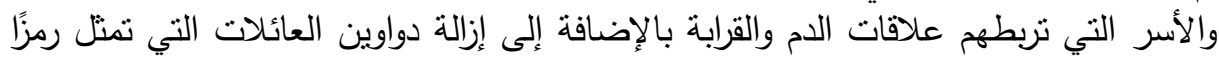

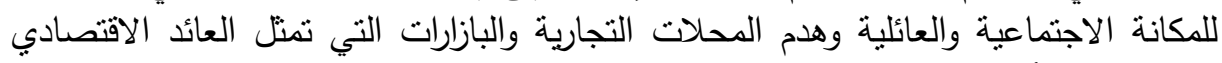

تهدف هذه الدراسة إلى التعرف على أسباب تهجير أهالي منطقتي الكرنك والقرنة

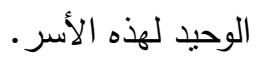

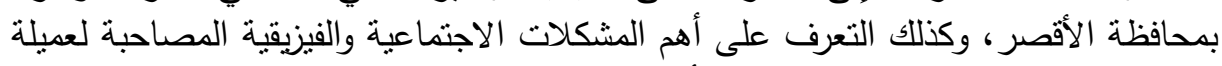

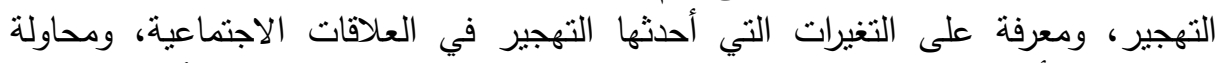

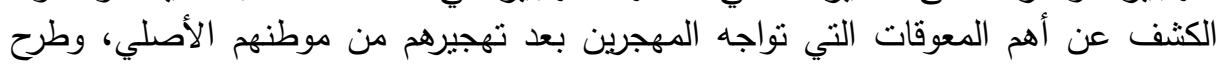

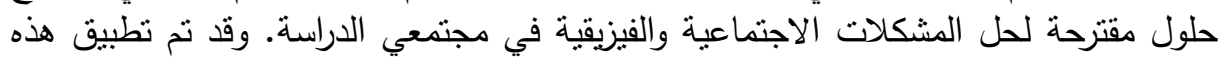

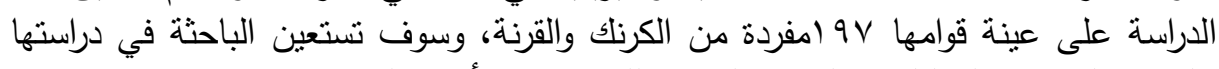

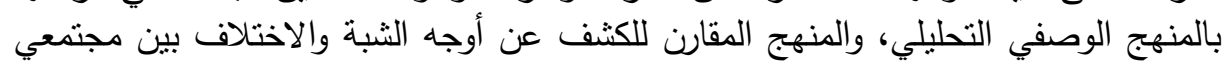

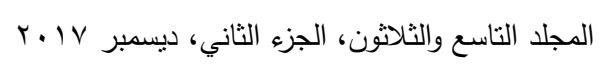


الدراسة، واعتمدت الدراسة الحالية على مجموعة من الأدوات منها استمارة الاستبيان، ودليل

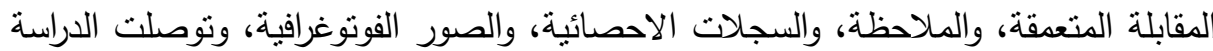

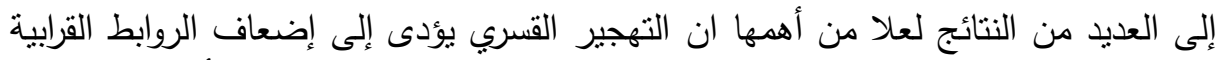

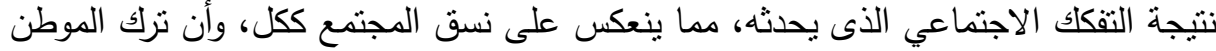

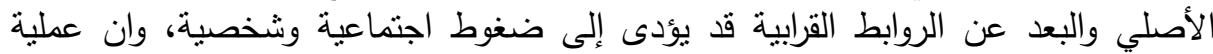

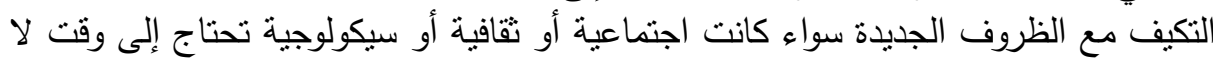

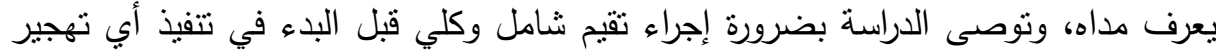

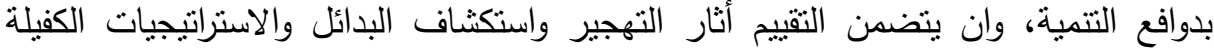

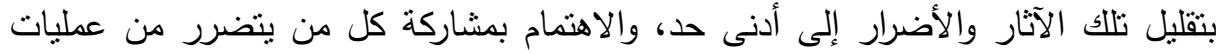

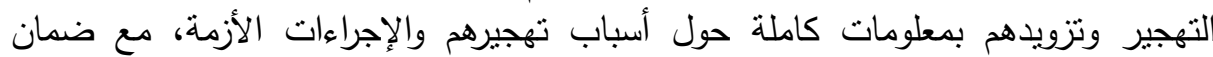

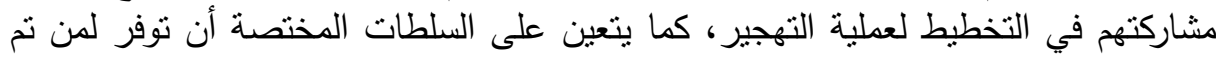

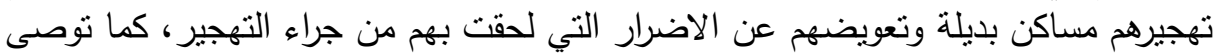

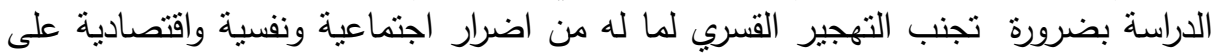

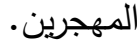

\section{sanadl}

تعد عملية التنمية هدف تسعى إليه المجمعات من اجل نقدم ورفاهية شعوبها والذين

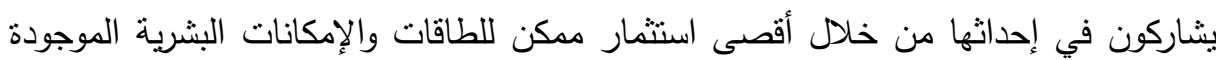
في المجتمع وحشد كافة موارد المجتمع المحلى، وما من سبيل لتحقيق هذه التتمية الإ بمشاركة

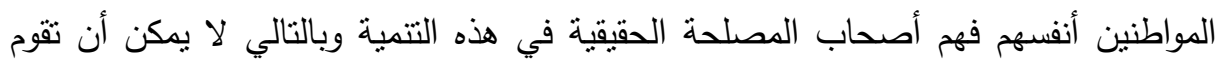
التتمية بدون استثارة المجتمع المحلى في تقرير مصيره وخاصة إذا كان القرار يتعلق بحياتهم

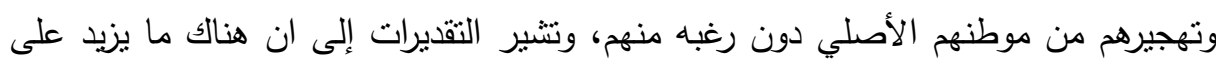
•

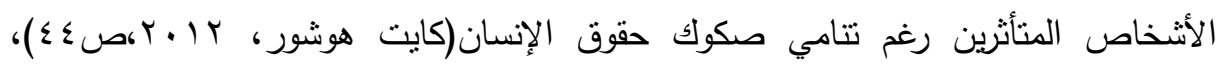
والمواثثق والاتفاقيات الدولية كاتفاقية جنيف ومعاهدة روما والإعلان العالمي لحقوق الإنسان التي تحرم التهجير القسري. 
ومن المعروف ان التهجير القسري ينطوي على مخاطر واستضعاف للأفراد لما يتضمنه

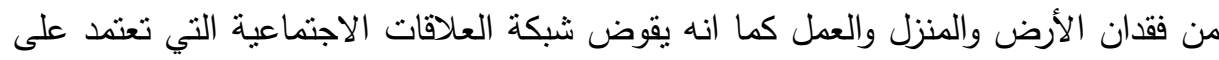
الناس وفيه أذى كبير وتحطيم للإنسان الذي به ومن اجله مقصد التتمية فما فائدة المشاريع

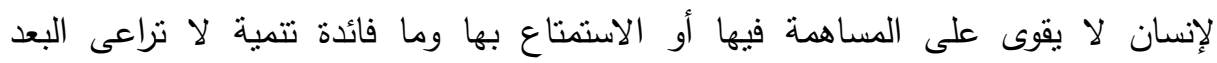

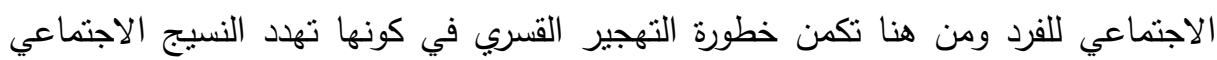

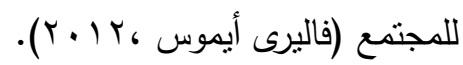

\section{xasty}

تعد محافظه الأقصر في صعيد مصر من اكبر المحافظات الأثرية حيث تحوي في

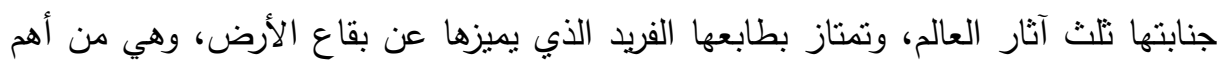

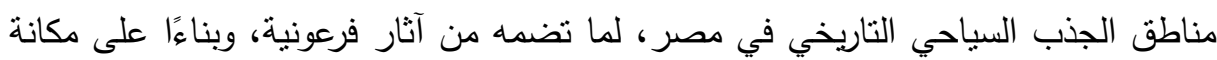

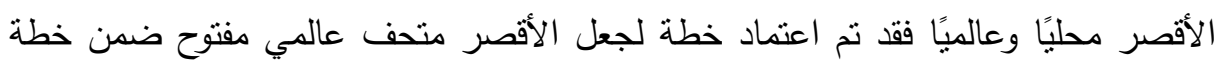

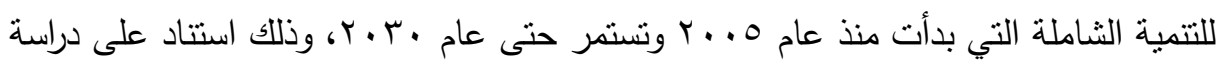

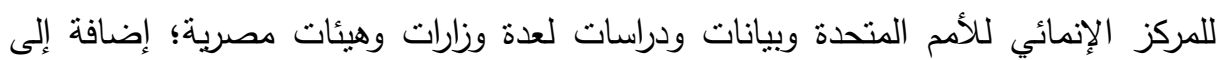
منظمة الأمم المتحدة للتربية والعلوم والثقافة "اليونسكو" التي تعد شريكًا أساسيًا باعتبار الآثار الفرعونية تراثا إنسانيًا، وشملت خطة النطوير إزالة التعديات من المنطقة الأثرية، وإعادة تخطيط المنطقة، وتحسين شكلها الحضاري لجذب المزيد من السياح، وشمل مشروع التطوير

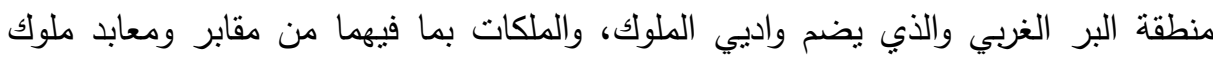

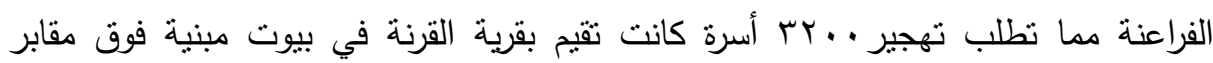

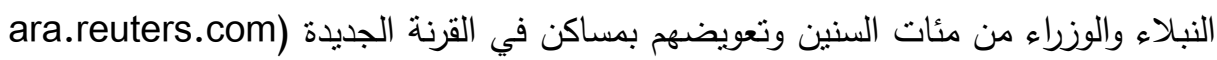

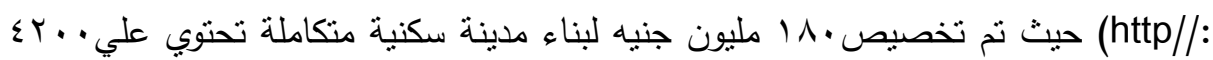

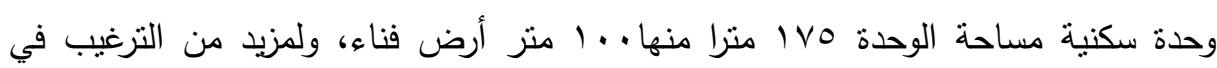
الانتقال تم تحديد . .0 قطعة أرض لمن لا برغب في في الوحدات السكنية لنقل جميع السكان.

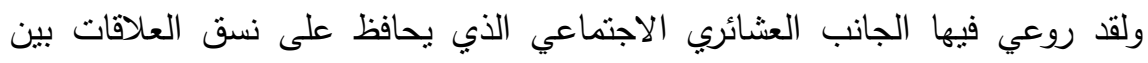

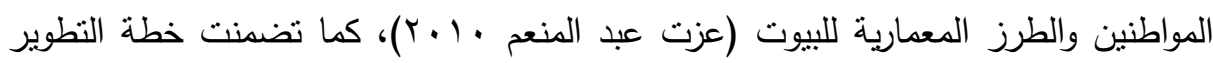

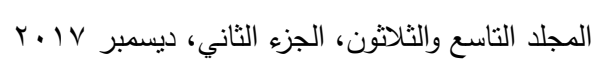




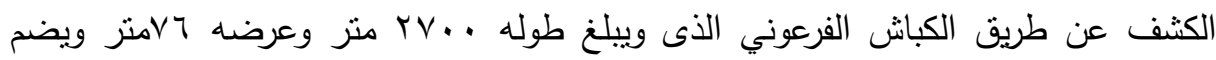
نحو .ا تمثال لأبو الهول وهو يعتبر أطول طريق ديني يربط بين معبدي الكرنك

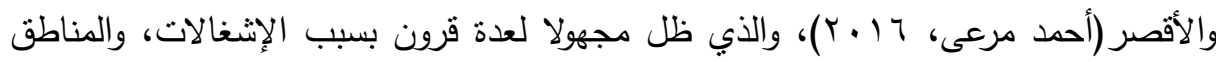

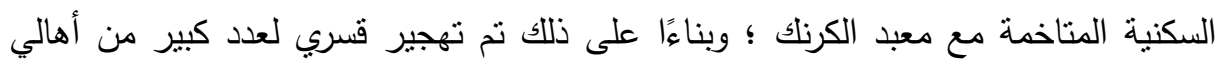

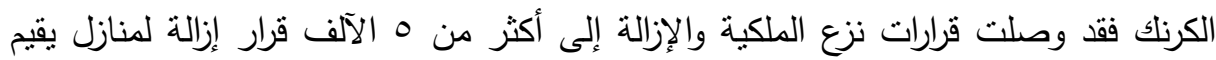

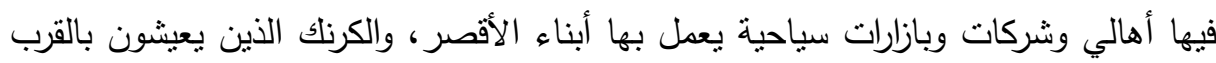

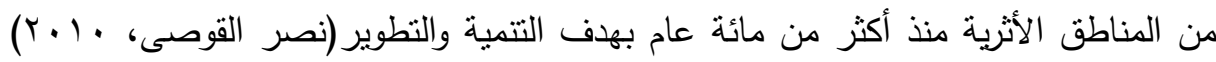
الذي لم براعى البعد الاجتماعي للمهجرين مما نرتب عليه تفكيك وتفتيت للعديد من العائلات والأسر التي تربطهم علاقات الدم والقرابة بالإضافة إلى إزالة (دواوين العائلات) التي تمثل

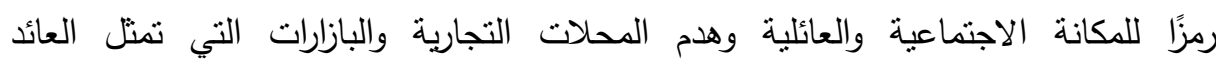

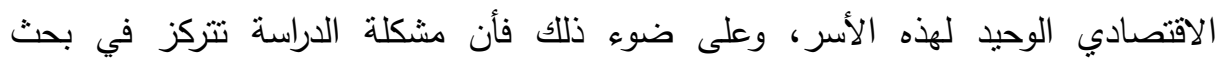
المشكلات الاجتماعية والفيزيقية لتهجير أهالي منطقتي الكرنك والقرنة وأثرها على العلاقات لهنه

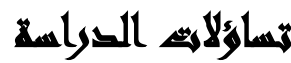

على ضوء الهرف الرئيس للاراسة الراهنة والأهداف الفرعية التي انبثقت عنه، وما تم

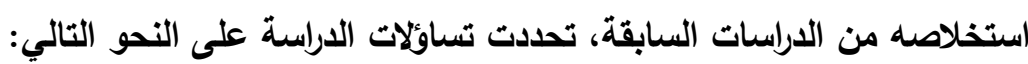

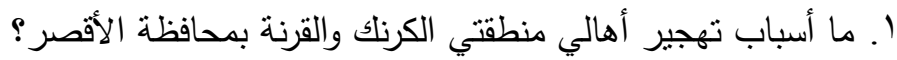

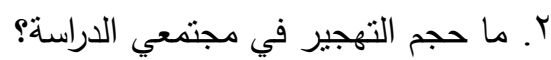

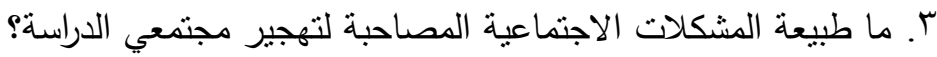
ع. ما نوعية المشكلات الفيزيقية المصاحبة لتهجير مجتمعي الدراسة؟

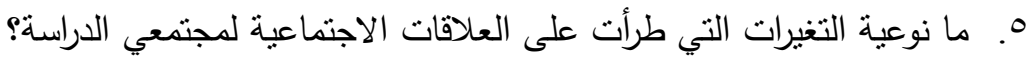

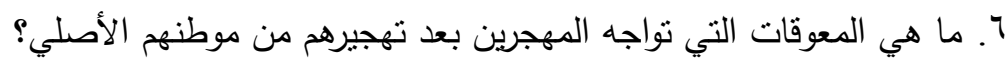

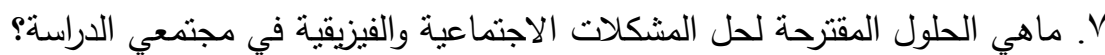

$$
\text { المجلد التاسع والثلاثون، الجزء الثاني، ديسمبر V V. T }
$$




\section{أهساهنغ التواسمة}

على ضوء ما طرحته فكرة الاراسة وطبيعة مشكلتها وما انتهت إليه نتائج الادبيات السابقة (المحلية والعالمية) حول الموضوع تحدد للاراسة هدف رئيس عام مؤداه: التعرف على التى المشكلات الاجتماعية والقيزيقية لتهجير أهالي منطقتي الكرنك والقرنة وأثرها على العلاقات الاجتماعية، وينبثق عن هذا الهذف عدة أهداف فرعية هي:

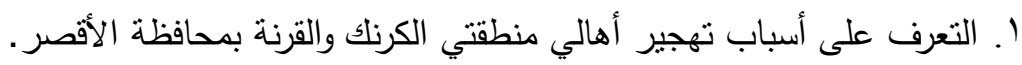
r. الكثف عن حجم التهجير في مجتمعي الدراسة الكرنك والقرنة. r. التعرف على أهم المشكلات الاجتماعية المصاحبة لعميلة التهجير في مجتمعي الدراسة. ع. البحث في المشكلات الفيزيقية المصاحبة لعملية التهجير في مجتمعي الدراسة. ๑. معرفة التغيرات التي أحدثها التهجير في العلاقات الاجنماعية لمجتمعي الدراسة. 7. الكثف عن أهم المعوقات التي تواجه المهجرين بعد تهجيرهم من موطنهم الأصلي. V. طرح حلول مقترحة لحل المشكلات الاجتماعية والفيزيقية في مجتمعي الدراسة.

\section{أهمية الدراسم}

وتتحدد أهية الاراسة الحالية في النقاط التالية:

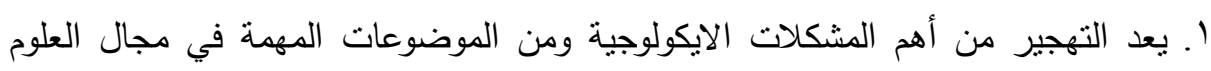

الإنسانية.

r. تتنمي هذه الدراسة إلى دراسات الإيكولوجية البشرية التي يهنم بها قسم العلوم الإنسانية.

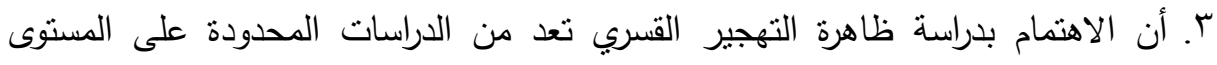
المحلى وظهر جليا في ندرة الدراسات العلمية الموجودة على الساحة.

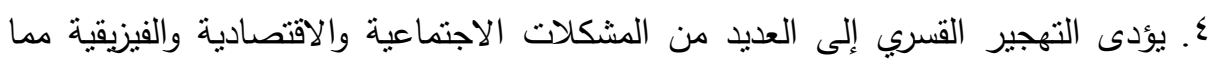

$$
\text { يكسب الدراسة الحالية أهمية بالغة. }
$$

○. تعد عملية التهجير التي نحن يصددها ثالث أكبر عملية تهجير بعد هجرة النوبيين فو بالغه القرنة القديمة في صعيد مصر مما يجعلها تستحق الدراسة والبحث.

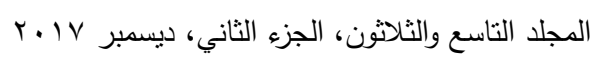




\section{وتتحدد أهمية الدراسة الحالية من الناحيتين النظرية والتطبيقية في التالي:}

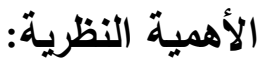

- تتمنل الأهمية النظرية لهذه الدراسة في كونها تعدو بمثابة اضافه علمية في مجال الايكولوجيا البشرية ويمكن الاسترشاد بها لما تتضمنه من مفاهيم، ومتغيرات وتساؤلات وأساليب إحصائية تفتح الآفاق لإجراء مزيد من الدراسات العلمية. - أن تتفيذ المشاريع التتموية والاهتمام بتتمية وتطوير المناطق الأثرية والتاريخية والدينية والمناطق المحيطة بها وظهورها بالمظهر اللائق أمام السياح والزوار، لا يعنى بالضرورة الاهتمام بالحجر على حساب البشر ، فلابد من مراعاة الجانب الاجتماعي والإنساني اثثاء عملية التهجير لتلافى الاثار النفسية والاجنماعية للتهجير القسري. الأهمية التطبيقية: جاءت الأهمية التطبيقية لموضوع الدراسة نتيجة لحاجة مجتمع صعيد مصر لهنل هذا النوع من الدراسات، وتعد تجربة نوطين القرنة نموذجا تتمويًا يحتذى به في

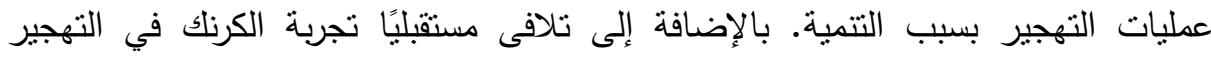
القسري الذى لم براعى فيها البعد الاجتماعي للمهجرين، ومن هنا كان اهتمام الباحثة بضرورة

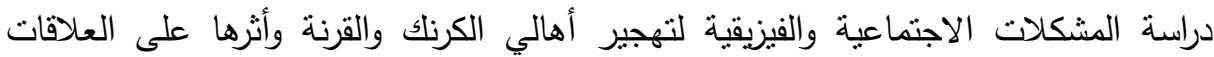

\section{مهاسهيو التراسة}

أولاً: مفهوم المشكلات الاجتماعية Social Problems: وتعرف المشكلة الاجتماعية بأنها: " طريقة السلوك التي بنظر إليها النظام الاجتماعي على أنها تمثل تعديا على أحد أو

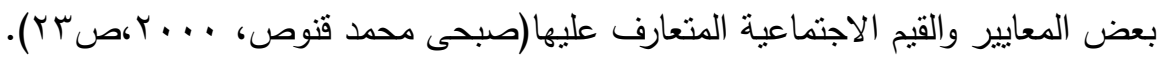
وقد أنشار البعض بأنها موقف ينثأ عندما يواجه الفرد عقبات أو صعوبة أو أمرًا يحول بينة وبين وصوله إلى هدف معين، أو لا يتمكن الفرد بما لديه من وسائل ومعلومات وخبرات من تخطى العقبات أو اجتيازها أو التغلب عليها مما يخلق حالة من عدم الاتزان والقلق في

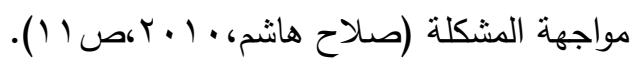


وفي القاموس الثامل لمصطلحات العلوم الاجتماعية تعرف المشكلة الاجتماعية على أنها ظاهرة اجتماعية ذات طابع خاص، و موقف يؤثر في عدد كبير من الأفراد حيث يعتقدون

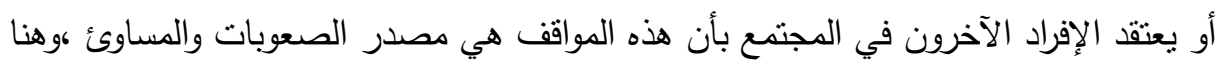

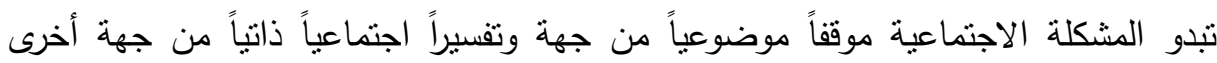
(حسان النوبى حجازى، 7 ( 1 (ب). المفهوم الإجرائي للمشكلة الاجتماعية :بقصد بالمشكلة الاجتماعية في ضوء الدراسة الراهنة المشكلات التي يتعرض لها المهرين قسريًا منها، مشكلات التفكلك الاجتماعي، مشكلات سوء الاهئه التكيف الاجتماعي. ثناتيًا: مفهوم المشكلة القيزيقية: The physical problem هي شكل من أشكال الإهمال والتخريب البيئي التي يقوم بها الإنسان اتجاه الموارد البيئية ومن أمثلة هذه الشككلات

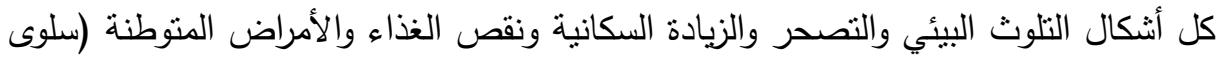

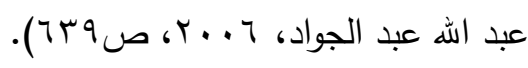
وتعرف أيضا بأنها كل تغير مباشر أو غير مباشر فيزيائي أو حراري أو بيولوجي أو أي

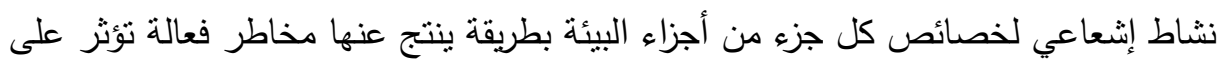
الصحة والأمن والرفاهية لكل الكائنات الحية الأخرى ( محمد حسين عبد القوى ، 1 ( ب ب).

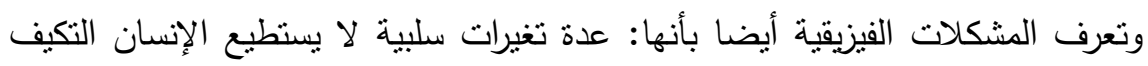

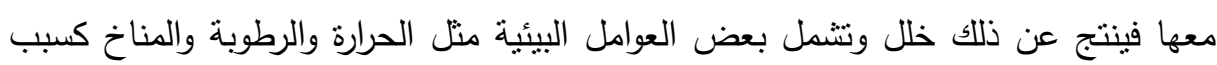

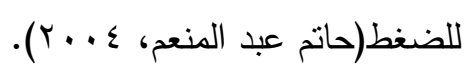

المفهوم الإجرائي للمشكلة الفيزيقية: يقصد بالمشكلات الفيزيقية في ضوء الدابدة الدراسة الراهنة:

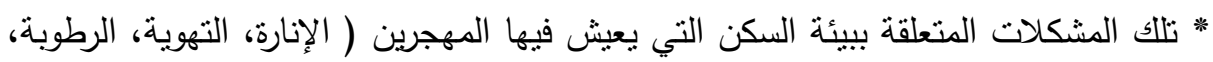

$$
\text { الازدحام ). }
$$

* المشكلات المتعلقة بيئة المنطقة السكنية للمهجرين( التلوث البيئي، التلوث الضوضائي ). * المشكلات المتعلقة بالخدمات (المياه، الصرف الصحي، المواصلات، توفر الخدمات

$$
\text { الصحية، توفر الخدمات الخدمية ). }
$$


ثالثًا: مفهوم التهجير Displacement: التهجير هو: الانتقال من منطقة إلى أخرى دون رغبة أو اختيار من المهاجرين حين تجبر السلطات بعض الأفراد على النزوح أو يطرد فرد أو جماعة حيث ينرك فيه المطرودين البلا دون تحديد مكان معين يذهبون إليه كالهجرات التي تمت إبان حكم هنلر والحركة النازية كما تتمثل عندما تقوم السلطات في الدولة بإجبار

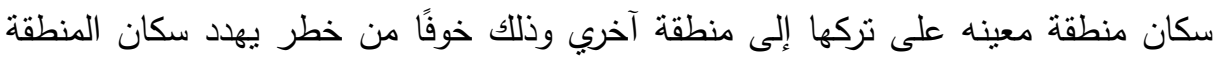

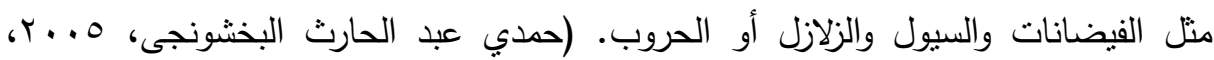

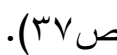

ويعرف التهجير بأنه: انتقال السكان تحت ضغط من الدولة أو الولاية أو قوة عسكرية ولا يستطيع المهاجر اتخاذ قرار الهجرة كما لا يستطيع تحديد موطن الإقامة الجديد (طارق السيد،

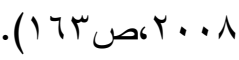
التعريف الإجرائي للتهجير: يقصد بالتهجير في هذه الدراسة التهجير الإجباري الذى تمارسه

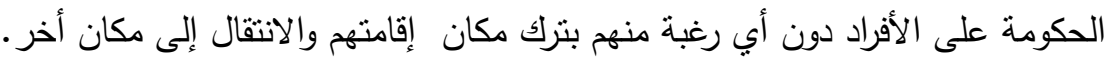
رابعًا: مفهوم العلاقات الاجتماعية Social relations: تعرف العلاقات الاجتماعية بأنها الروابط والصلات التي تظهر في السلوك والممارسات والتفاعلات التي تتشأ بين فردين أو أكثر من أفراد المجتمع(Marina and Melanie killen,1998). وتعرف بأنها نسق معين ثابت يشتنل على طرفين " فردين أو جماعتين " تربطهم

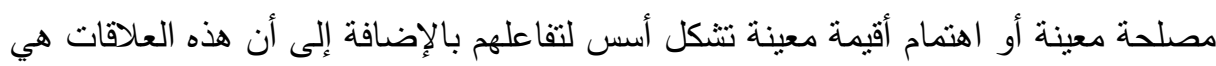

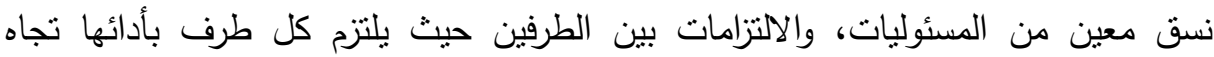

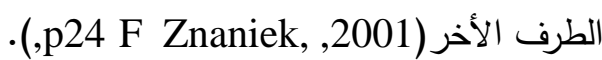

أما ماكس فيبر فيشير إليها باعتبارها الموقف الذي من خلاله يدخل شخصان أو أكثر

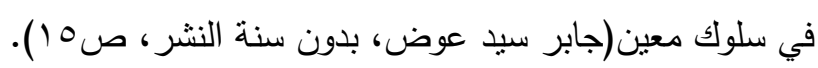

التعريف الإجرائي للعلاقات الاجتماعية: يقصد بالعلاقات الاجتماعية في ضوء الدراسة الراهنة

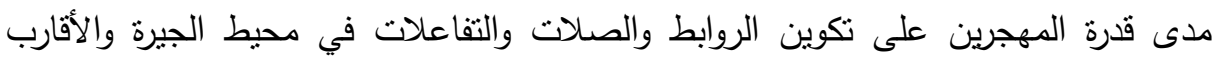
والأصدقاء 


\section{الإطال اللنظيه السوراسة}

تمثل المنطلق النظري لهذه الدراسة في عدد من النظريات منها على النحو التالي: النظرية البنائية الوظيفية: Functional theory: تقوم النظرية البنائية الوظيفية كغيرها من النظريات السوسيولوجية على عدد من المقولات أو الأفكار الأساسية التي تتطلق

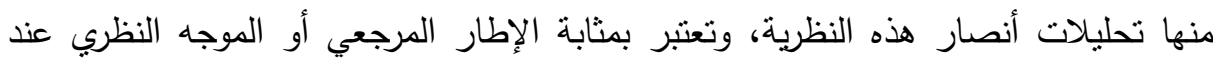

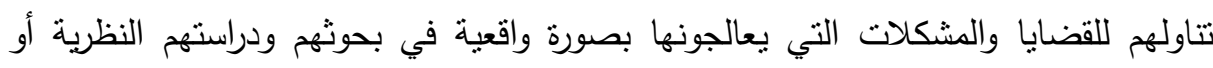

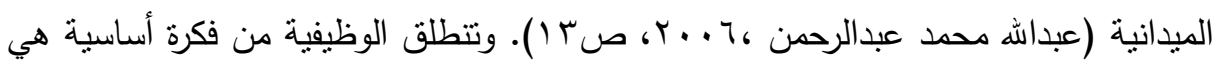

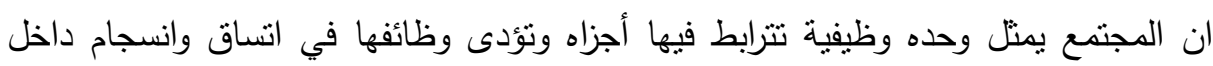

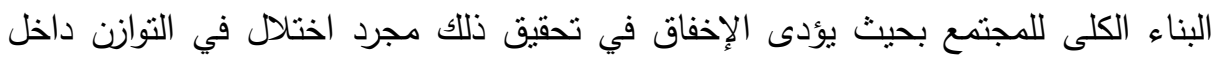

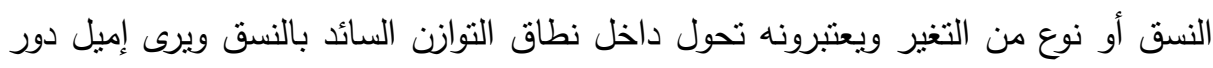

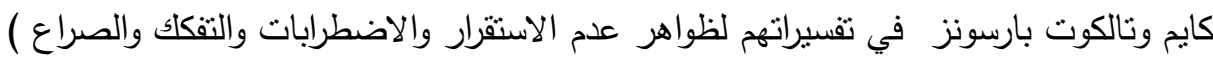
الموجودة في كل مكان وزمان ظواهر انحراف شاذة ومرضية(جون ركس، بدون سنة النشر .) (1) (1) (1) نظرية النسق الايكولوجي: تقوم محاور ومنطلقات النظرية الايكولوجية على مجموعة

$$
\text { محددات انطلقت منها تعاريفها وهى كالآتي: }
$$

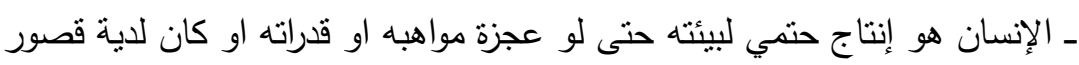

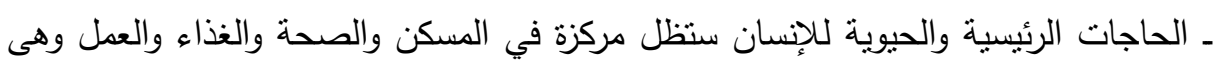

$$
\text { كلها إمكانيات تحددها أولا البيئة وليس الإنسان. }
$$

ـ ان اى علاج فردى بعيدا عن البيئة هو علاج بطئ وقليل الفاعلية (عبدالفتاح عثمان بدون الإنان الفيان

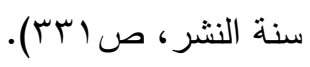

فرضيات وخصائص النظرية الايكولوجية: ـ ترى أن البيئة مصدر سعادة الإنسان وشقائه. ـ تفترض الإنسان كائن بيئي أوجدته وشكلته بل وأثنارت مشاكله البيئة أولا وأخيرا. 
ـ كافة مضاعفات الإنسان النفسية وأزماته الأخلاقية والسلوكية هى استجابات لعجز البيئة عن إثباع احتياجاته الذاتية والحيوية. - حاجات الإنسان البيولوجية هي حقيقة الوجود الإنساني ويحددها المسكن والغذاء والعمل

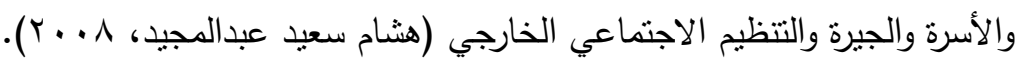
ويعرف النسق فى ضوء النظرية الايكولوجية بأنه مجموعة من العناصر أو الأجزاء

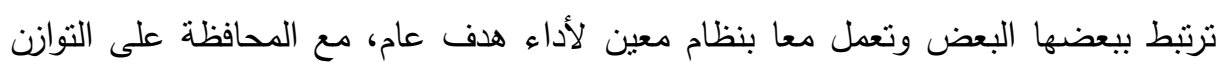

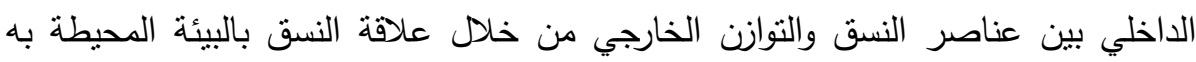
(Etienne Winger,1999,p241)

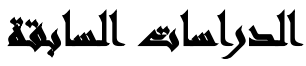

أولاً: الاراسات التي تتاولت المشكلات الاجتماعية والبيئية:

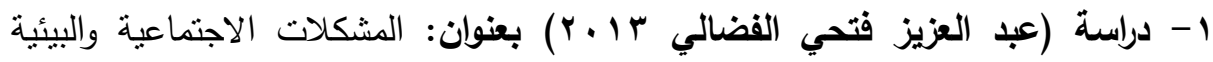
المرتبطة بالزحف العمراني على منطقة معبد أسنا بتقنيات الاستشعار من بعد ونظم

المعلومات الجغرافية.

تهذف الدراسة إلى التعرف على التغيرات التي لحقت بالأنساق الاجتماعية مثل نسق الأسرة

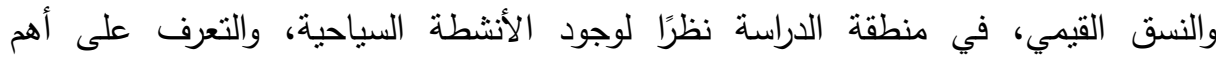
المشكلات البيئية التي لحقت في استخدام الأرض، وأثرها على سكان المنطقة وعلى المنشآت لهنه الأثرية، وتتنمى هذه الدراسة إلى الدراسات الوصفية التحليلية وقد قام الباحث باختيار مركز

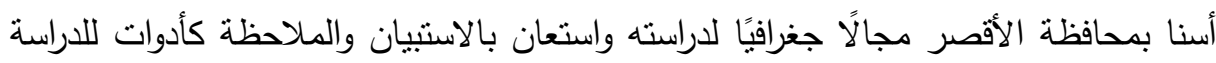
وتم تطبيق الدراسة على عدد ؟ ا مفردة من السكان المحلين والعاملين بأنشطة مرتبطة بالسياحة، وقد توصلت الدراسة إلى العدبد من النتائج لعل من أهمها:

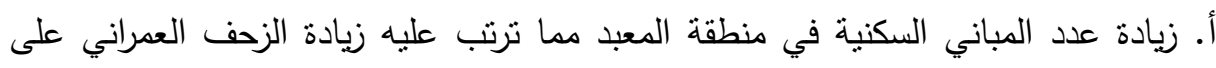

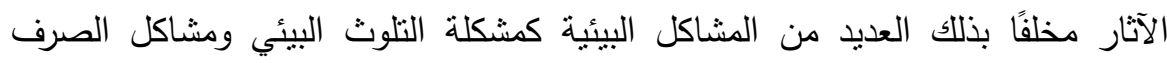
الصحي ومشاكل مخلفات الطيور • 
ب. يعانى أفراد الدراسة من مشاكل اجتماعية عديدة منها الفقر والبطالة وتسرب الأطفال من التعليم مما أدى لوجود مشاكل أخرى كضعف المشاركة المجتمعية، وضعف الانتماء. ت. يعانى مجتمع الدراسة من العديد من المشاكل البيئية منها انتشار القمامة، المياه الجوفية،

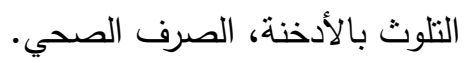
r- دراسة (طارق غازي بازرعه 9 . . ب) بعنوان: الدراسات البيئية لتطوير المناطق التراثية في مدن وادي حضرموت. تهـف الدراسة إلى دراسة الوضع الراهن لبعض الدناطق بالمدن التراثية والمعمارية والتي

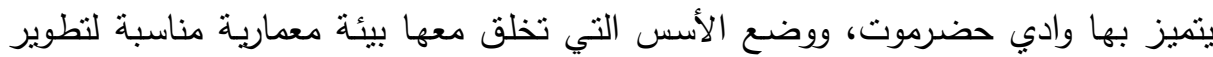
هذه المناطق، وقد استخدم الباحث مدن وادي حضرموت وهي سيؤن وتريم وشبام والقطن مجالا جغرافيا لدراسته، وتوصلت الدراسة إلى العدبـ من النتائج: • تدور بعض الأبنية التراثية وعدم الاهتمام بها مما يهددها بالزوال. • ـهور عدد من الأبنية الخرسانية التي تهدد الهوية المعمارية للمنطقة.

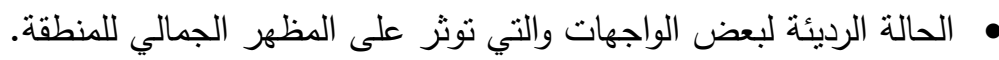
ثانيًا :الاراسات التي تناولت التهجير:

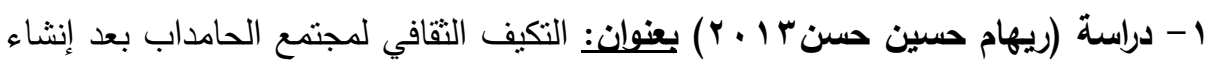
سد مروى بالسودان دراسة في الانثروبولوجيا الثقافية).

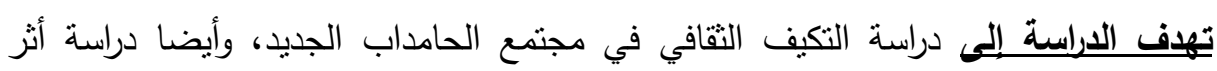
التهجير على نفسية أفراده ومعرفه مظاهر ، وأسباب المشكلات الثقافية والاجتماعية والبيئية والصحية التي تصاحب التهجير والحلول المقترحة لحلها، وقد استعانت الباحثة بأربعة مناهج

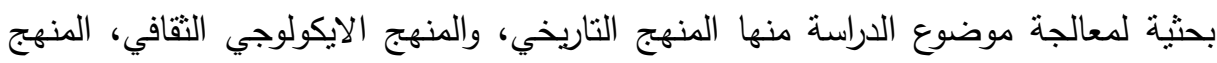
الوصفي التحليلي، المنهج المقارن وتم اختيار منطقة الحامداب كمجال جغرافي لتطبيق ولني الدراسة، توصلت الدراسة إلى العديد من النتائج لعل من أهمها: أ- أن التهجير الإجباري لا يؤدى إلى التكيف التقافي، وعلى الرغم من عدم نوفر الخدمات الاجتماعية بمجتمع الدراسة إلا أن أفراده يحاولون التكيف مع الصعوبئ الصيات التي تقابلهم.

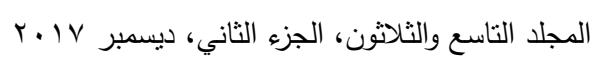


ب- أن عملية التهجير وما يرتبط بها من عامل الإجبار لترك الموطن الأصلي جعلت المهجرين يشعرون بحساسية شديدة اتجاه الصعوبات والمعوقات التي يواجهونها فيلقون المسئولية على الجهة المنفذة، ومن هنا يظهر الفرق بين التهجير الإجباري وبين المهجرين بندين بونين

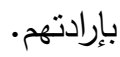

ت- المشكلات التي تواجه مراحل التهجير والتوطين أحد أسبابها الرئيسية هي عدم مشاركة السكان المنيين في مراحل التخطيط والتصميم والتنفيذ.

ث- وتمثلت المشكلات الاجتماعية في ظهور حالات السرقة وجرح الخصوصية لعدم ملائمة تصميم المنازل لطبيعة المهرين؛ أما المشكلات البيئية فتمثل في عدم الثعور بالراحة الحرارية داخل المسكن الجديد. ץ- دراسة:) Guataquí Roa, J.C, 2006 ) بعنوان: التهجير القسري والهجرة الداخلية في كولومبيا. تسعى هذه الدراسة إلى تحليل قضية التهجير القسري في كولومبيا، في الفترة من بو 199 حتى 199

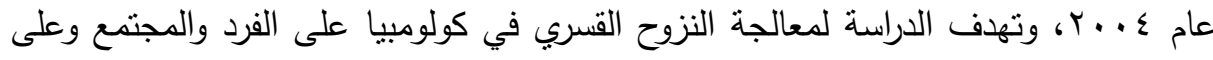
المستوى القومي، وسعت الدراسة لتوصيف مفهوم التهجير القسري بشكل صحيح كواحد من في ونسي

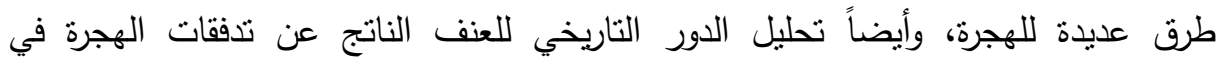
كولومبيا، وتوصلت الدراسة إلىى العديد من النتائج لعل من أهمها: استخدم السلطات العديد

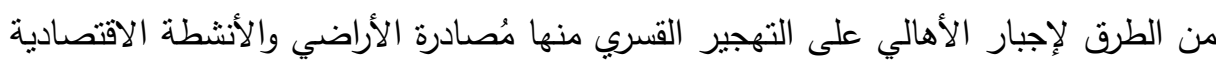

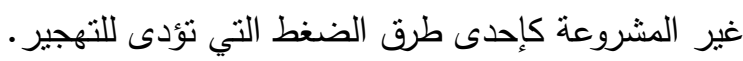
ثالثًا: الدراسات التي تناولت العلاقات الاجتماعية: 1- دراسة (أمل عبد الستار عبدالوهاب 11 1 ب) بعنوان: ثأثثير النمو العمراني على العلاقات الاجتماعية للأسر الممتدة دراسة أنثروبولوجية بمدينة مغاغة محافظة المنيا). تهرف الاراسة إلى التعرف على تأثثير النمو العمراني على العلاقات الاجتماعية للأسرة

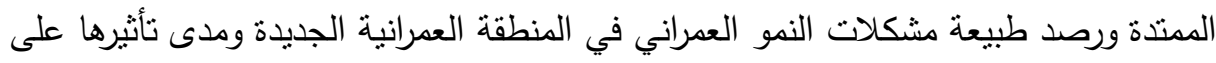
طبيعة العلاقات الأسرية وبخاصة الأسرة الممندة وأيضا رصد طبيعة العلاقات الاجتماعية 
للأسر الممتدة مع الجيران، الأقارب، الأصدقاء، وتتنمى هذه الدراسة إلى الدراسات الوصفية،

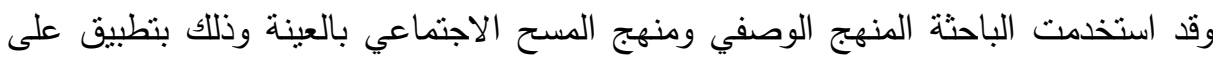

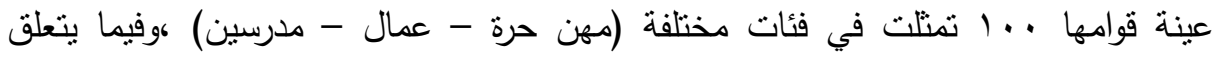
بأدوات جمع البيانات اعتمدت الباحثة على استمارة الاستبيان في موقف المقابلة، دليل المقابلات المتعقة، بالإضافة إلى الأسلوب الإحصائي لتحليل البيانات، وكذلك السجلات التيلات والوثائق، وتوصلت الدراسة إلى عدد من النتائج من أهمها:

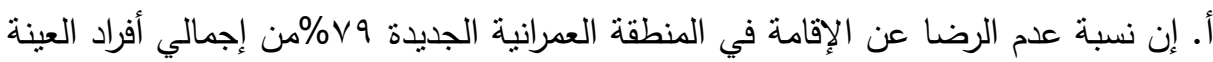
وأوضحت النتائج أن الدولة لم نراعى في المناطق العمرانية الجديدة البنية الأساسية

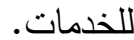

ب. اتضح من خلال الدراسة الميدانية أنه على الرغم من طبيعة البناء والتناسق والقرب بين

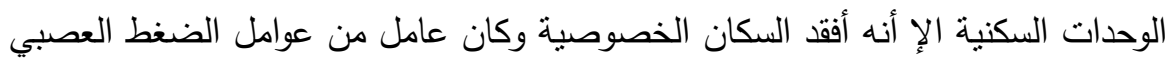

$$
\text { على السكان مما أدى إلى توتر العلاقات الاجتماعية. }
$$

r- دراسة (حاتم عبدالمنعم 1990) بغنوان: العلاقة بين الرضا عن المسكن والعلاقات الاجتماعية دراسة مقارنة بين الريف والحضر .

يهذف هذا البحث إلى دراسة العلاقة بين الرضا عن المسكن والعلاقات الأسرية، ودراسة

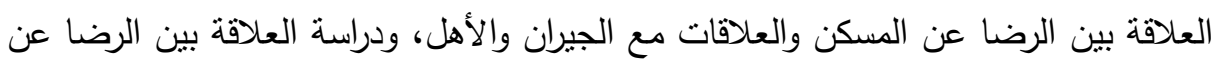
المسكن والمشاركة في أنشطة المجتمع المحلى، ومقارنة العلاقات الاجتماعية بين الريف والحضر، واستخدم الباحث في دراسة المسح الاجتماعي بالعينة واستعان بالعديد من الأدوات منها استمارة إستبار ومقاييس العلاقات الاجتماعية ومقاييس الرضا عن المسكن وتم نطبيق

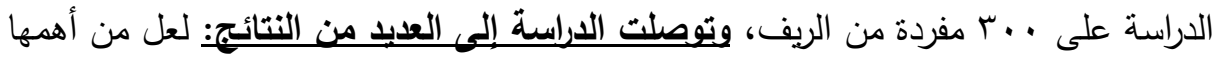
وجود علاقة بين الرضا عن المسكن والعلاقات الأسرية والعلاقات مع الأهل والجيران، وأيضًا توجد علاقة بين الرضا عن المسكن والمشاركة في أنشطة المجتمع المحلى، وتتشير الدراسة الدانة إلى أن الفرد عندما يكون على علاقة طيبة مع الجيران يشعره ذلك بالرضا عن منزله. 


\section{الإجراءائ المنهجية للسراسلة}

أولاً: منهج الدراسة: سوف تستعين الباحثة في دراستها بالمنهج الوصفي التحليلي، والمنهج المقارن للكثف عن أوجه الثبة والاختلاف بين مجتمعي الدراسة.

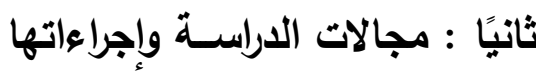

ا. المجال البشرى: ويقصد به الأفراد الذين جمعت منهم البيانات عن طريق الحصر الثامل

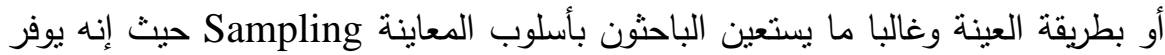

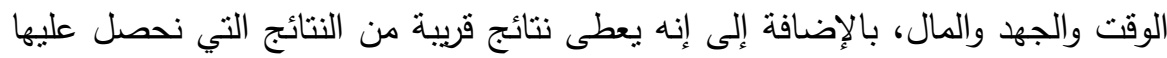

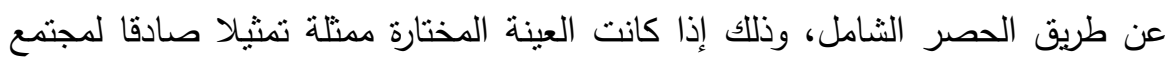
الدراسة، وقد اختارت الباحثة مفردات دراستها من الأسر المهجرة من منطقتي الكرنك الكتاك والقرنة.

r. المجال الجغرافي: يقصد به المجتمع الذي يقوم الباحث باختباره لإجراء دراسته الميدانية (قرية - مدينه - مصنع - جامعة - الخ) وقد وقع اختيار الباحثة على (البنى الجديدة، لبادية

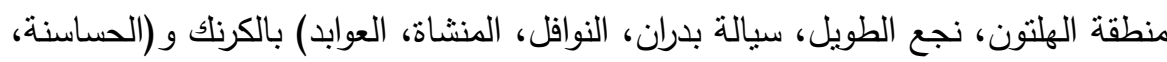
العطيات، قرية مرعى، الحروبات، الغابات) بالقرنة الجديدة.

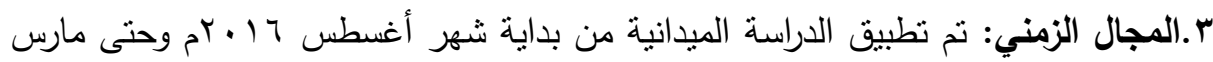

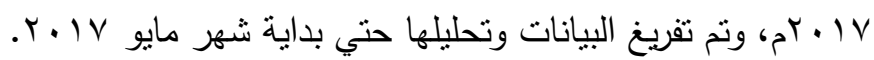

ثُاثثًا: عينة الدارسة: يتمتل مجتمع البحث فى قاطنى القرنة الجديدة ومنطقه الكرنك، وقد تم تطبيق الدراسة الميدانية على 19 19 مفردة من الأسر المجرة من منطقه القرنة الجديدة بالبر

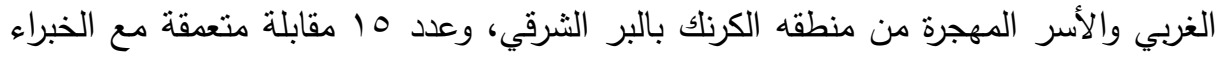
والمسئولين، وعدده الفراد من الاخبارين. رابعًا: أدوات الداراسة: اعتدت الدراسة الحالية على مجموعة من الأدوات منها الاستيبان، ودليل المقابلة المتعمقة، الملاحظة، والاخباريين. 
الثبات والصدق للاستبيان:

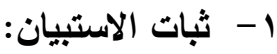

جدول رقم(1): يوضح : ثبات العبارات لأبعاد الاستبيان

\begin{tabular}{|c|c|c|}
\hline قألفاة & العبارات & أبعاد الاستبيان \\
\hline 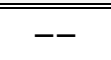 & 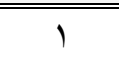 & أسباب تهجير أهالى منطقتى الكرنك والقرنة بمحافظة الأقصر \\
\hline$\cdot, \wedge \wedge 9$ & $\mathrm{~V}$ & كيفية تهجير أهالى الكرنك والقرنة بمحافظة الأقصر \\
\hline$\cdot, 9 \cdot 7$ & 7 & أهم المشكلات الاجتماعية الخاصة بتهجير مجتمعي الدراسة \\
\hline$\cdot, 9 \leq Y$ & $\varepsilon$ & المشكلات الفيزيقية الخاصة لتهجير مجتمعي الدراسة \\
\hline$\cdot, 909$ & $\Lambda$ & أثز التهجير على طبيعة ونوعية العلاقات الاجتماعية لمجتمعي الدراسة \\
\hline$\cdot, 9 \wedge$. & $r$ & المشكلات التي تواجه المهجرين بعد تهجيرهم من موطنهم الأصلي \\
\hline$\cdot, 9 \wedge \mathrm{r}$ & trV & إجمالي الاستبيان \\
\hline
\end{tabular}

يتضح من الجدول ( 1 ) أن قيم معاملات الثبات جميعها قيم مرتفعة حيث بلغت قيم

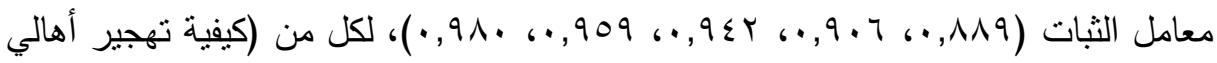

منطقتي الكرنك والقرنة بمحافظة الأقصر، أهم المشكلات الاجتماعية الخاصة بتهجير

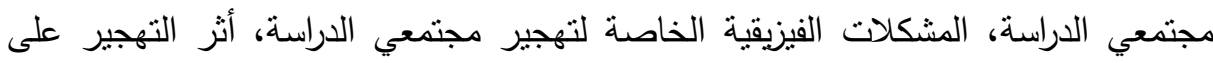

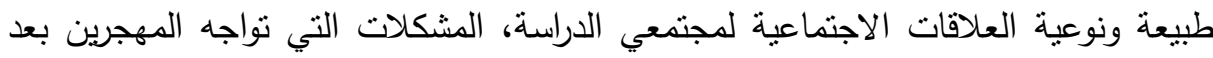

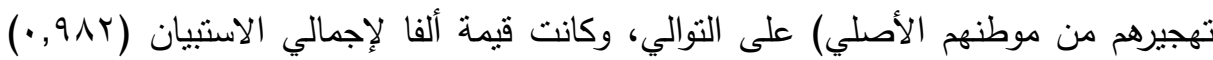
وهي قيمة مرتفعة وتثير هذه القيم من معاملات الثبات إلى صلاحية العبارات وإمكانية الاعتماد على نتائجها والوثوق بها.

صدق الاتساق الداخلي للاستبيان: نم حساب معاملات ارتباط كل بعد من أبعاد الاستبيان

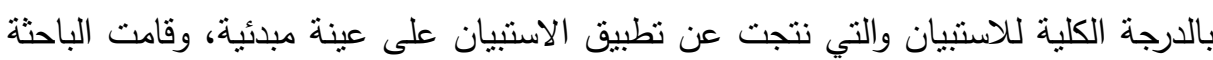
بحساب صدق الاتساق الداخلي ومعامل الارتباط المصحح كالآتي : 
جدول رقم(Y): يوضح صدق الاتساق الداخلي لأبعاد الاستبيان

\begin{tabular}{|c|c|c|}
\hline إجمالي الاستبيان & \multicolumn{2}{|r|}{ المتغـــــرات } \\
\hline$(* *) \cdot, T \cdot V$ & معامل ارتباط بيرسون & \multirow{2}{*}{ أسباب تهجير أهالي منطقتي الكرنك والقرنة } \\
\hline$\cdot, \ldots 1$ & الدلالة المعنوية & \\
\hline$(* *) \cdot, q \uparrow q$ & معامل ارتباط بيرسور & \multirow{2}{*}{ كيفية تهجير أهالي منطقتي الكرنك والقرنة } \\
\hline$\cdot, \ldots 1$ & الدلالة المعنوية & \\
\hline$(* *) \cdot, \wedge 70$ & معامل ارتباط بيرسور & \multirow{2}{*}{ 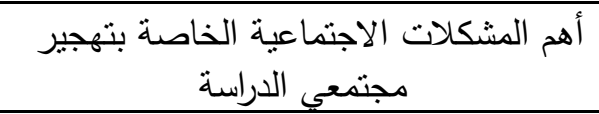 } \\
\hline$\cdot, \ldots 1$ & الدلالة المعنوية & \\
\hline$(* *) \cdot, 9 \vee r$ & معامل ارتباط بيرسون & \multirow{2}{*}{ المشكلات الفيزيقية الخاصة لتهجير مجتمعي } \\
\hline$\cdot, \ldots 1$ & الدلالة المعنوية & \\
\hline$(* *) \cdot, 9 \vee \mathrm{V}$ & معامل ارتباط بيرسون & \multirow{2}{*}{ 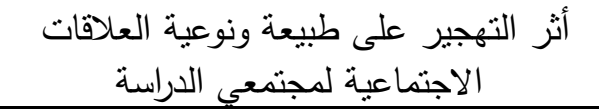 } \\
\hline$\cdot, \ldots 1$ & الدلالة المعنوية & \\
\hline$(* *) \cdot, 9 \leqslant 0$ & معامل ارتباط بيرسون & \multirow{2}{*}{ المشكلات التي تواجه المهجرين بعد تهجيرهم } \\
\hline$\cdot, \ldots 1$ & الدلالة المعنوية & \\
\hline
\end{tabular}

من جدول صدق الاتساق الداخلي السابق لأبعاد الاستبيان نجد أن معامل الارتباط بين

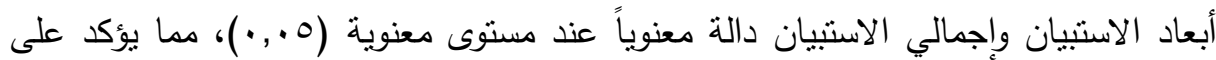

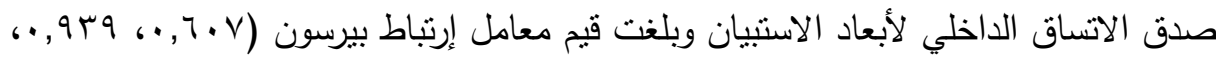

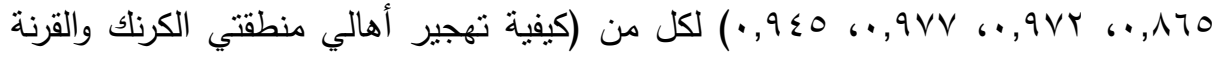
بمحافظة الأقصر، أسباب تهجير أهالي منطقتي الكرنك والقرنة بمحافظة الأقصر، أهم المشكلات الاجتماعية الخاصة بتهجير مجتمعي الدراسة، المشكلات الفيزيقية الخاصة لتهجير مجتمي الدراسة، أثز التهجير على طبيعة ونوعية العلاقات الاجتماعية لمجتمي الدراسة، المشكلات التي تواجه المهرين بعد تهجيرهم من موطنهم الأصلي) على التوالي. 


\section{نئائي السراسلة}

أولاً: أسباب التهجير بمنطقتي الكرنك والقزنة بمحافظة الأقصر : جدول رقم(ّ): يوضح أسباب تهجير أهالي منطقتي الكرنك والقرنة بمحافظة الأقصر من منازلهم

\begin{tabular}{|c|c|c|c|c|c|c|c|c|c|}
\hline \multirow{2}{*}{ المعنوية } & \multirow[b]{2}{*}{ كاץ } & \multirow[b]{2}{*}{ الترتيب } & \multicolumn{2}{|c|}{ إجمالي العينة } & \multicolumn{2}{|c|}{ القرنة } & \multicolumn{2}{|c|}{ الكرنك } & \multirow[b]{2}{*}{ الأسباب } \\
\hline & & & النسبة & العدد & النسبة & العدد الع & النسبة & العدد العد & \\
\hline$\cdot, \cdots r$ & 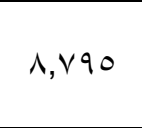 & 1 & $\wedge \varepsilon, \Gamma$. & 177 & $V 7,0$ & vo & 91,9 & 91 & منطبة بيني كان الآثار من \\
\hline$\cdot, \xi$ & $\cdot, 710$ & V & rv,T. & $V \leq$ & $r \varepsilon, V$ & $r \varepsilon$ & $\varepsilon \cdot, \varepsilon$ & $\varepsilon$ & 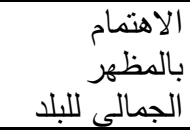 \\
\hline$\cdot, \cdots$ & IT,T & 7 & $\varepsilon \cdot, 7$. & $\Lambda$. & - & - & $\wedge \cdot, \wedge$ & $\wedge$. & طرين الكثف الكباش عن معبدي \\
\hline$\cdot, \cdots$ & $9 \vee, Y 90$ & 0 & $\varepsilon r, 1$. & 10 & $\Lambda, r$ & $\wedge$ & $\vee \vee, \Lambda$ & $V V$ & الأقفيذ \\
\hline$\cdot, \cdot \varepsilon$ & $\varepsilon, 1 \wedge \varepsilon$ & r & $V T, 1$. & $1 \leqslant \varepsilon$ & $\vee 9,7$ & $\vee \wedge$ & $77, \vee$ & 77 & العثرة \\
\hline$\cdot, \cdots$ & $10 \leqslant, 1 \wedge 1$ & $\varepsilon$ & $\varepsilon r, V$. & $\wedge 7$ & $\wedge \vee, \wedge$ & $\wedge 7$ & - & - & الخدالمنات \\
\hline$\cdot, \cdot \Sigma$ & $\varepsilon, r \leq r$ & r & 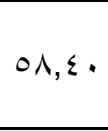 & 110 & 01 & 0. & $70, V$ & 70 & 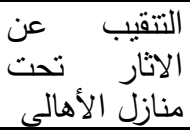 \\
\hline$\cdot, \cdots$ & OV,VTr & $\wedge$ & $r r, \Lambda$. & $\leqslant 0$ & - & - & $\leqslant 0,0$ & $\leqslant 0$ & تلفيغ الكنف المنطقة \\
\hline
\end{tabular}

المجلد التاسع والثلاثون، الجزء الثاني، ديسمبر V V r T 
باستقراء بيانات الجدول رقم (r) يتبين تعد الاستجابات الخاصة بأسباب تهجير أهالي

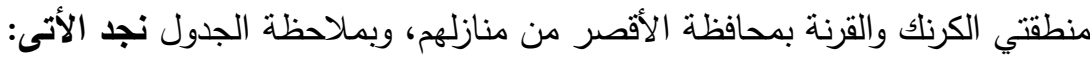

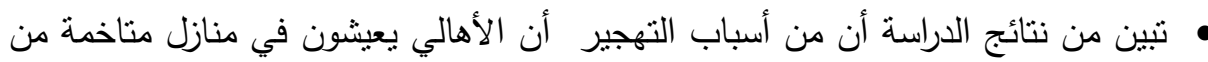

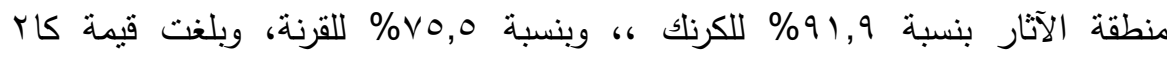

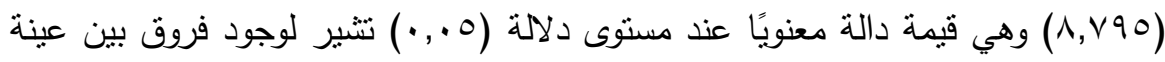

• أثنارت نتائج الدراسة أن معظم المناطق الموجودة حول المناطق الاثرية تفتقد للتخطبط

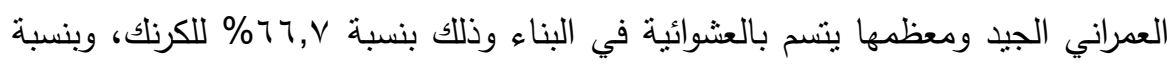

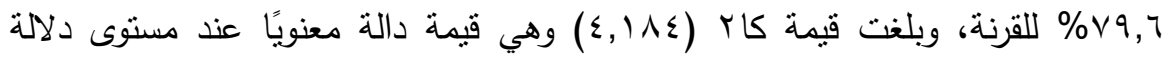
(0. . •) تشير لوجود فروق بين عينة الدراسة. وتتفق هذه النتيجة مع دراسة (عبد العزيز فتحي الفضالي ) التي تؤكد أن زيادة عدد المباني السكنية في منطقة المعبد؛ يتزتب عليها زيادة الزحف العمراني على الآثار . • أكدت نتائج الدراسة أن التتقيب عن الاثار تحت منازل الأن . ألهالي من الأسباب الرئيسية لإزالة

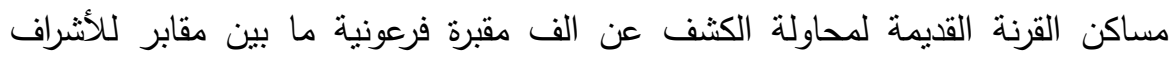
وأخرى للفقراء مدفونة تحت . . م منزل، والسبب الرئيسي لإزالة بيوت الكرنك لانهم

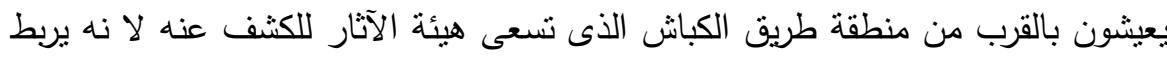

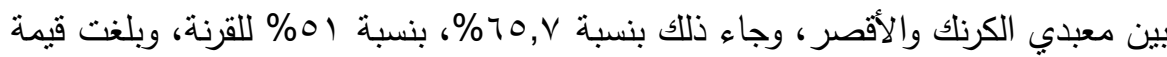

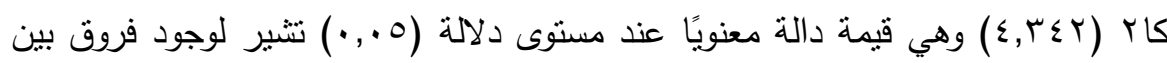
عينة الدراسة. تنبين من نتائج الدراسة أن تدهور الخدمات بالمناطق الخدمات الاساسية من مياه شرب

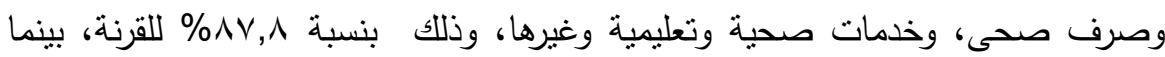

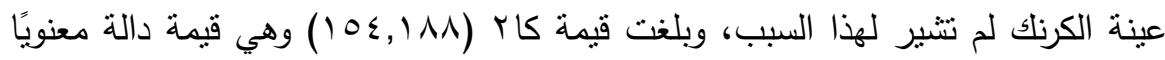

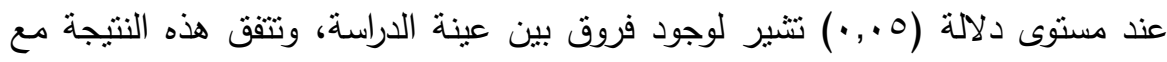

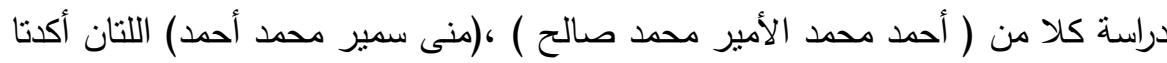

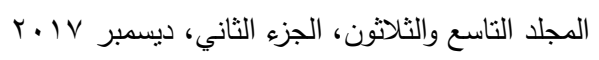


على توفر العديد من الخدمات بمجتمع الكرنك منها على سبيل المثال توفر المدار، والمستشفيات، والوحدات الصحية، وخدمات تتظيم الأسرة ومخابز .

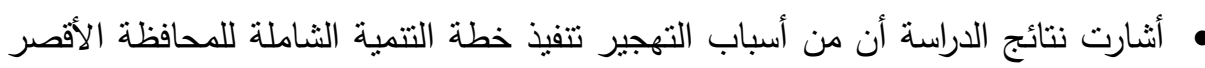

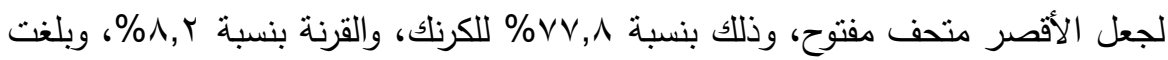

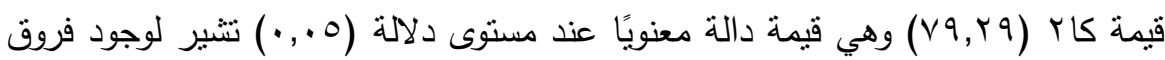
بين عينة الدراسة.

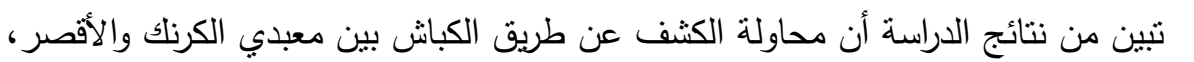

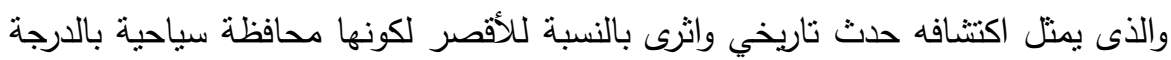

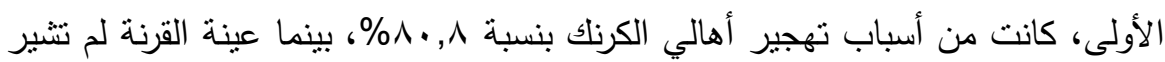

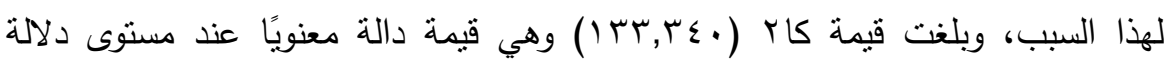
(0) 0 , • ) تشير لوجود فروق بين عينة الدراسة.

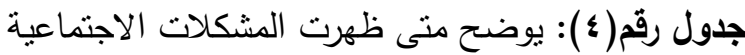

\begin{tabular}{|c|c|c|c|c|c|c|c|c|c|c|c|c|c|c|c|c|c|}
\hline \multirow{3}{*}{ "is } & \multicolumn{4}{|c|}{ لائرج شئ } & \multicolumn{4}{|c|}{$A$ Af } & \multicolumn{4}{|c|}{ 5 } & \multicolumn{4}{|c|}{ 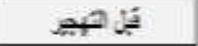 } & \multirow{3}{*}{ 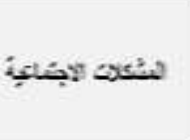 } \\
\hline & \multicolumn{2}{|c|}{ مري } & \multicolumn{2}{|c|}{2,0} & \multicolumn{2}{|c|}{ مر } & \multicolumn{2}{|c|}{2,5} & \multicolumn{2}{|c|}{40} & \multicolumn{2}{|c|}{20} & \multicolumn{2}{|c|}{80} & \multicolumn{2}{|c|}{20} & \\
\hline & $\%$ & $a$ & $\%$ & $z$ & $\%$ & $z$ & $\%$ & $\varepsilon$ & $\%$ & $\varepsilon$ & $\%$ & $z$ & $\%$ & $a$ & $\%$ & $g$ & \\
\hline$-10 ., 1$. & $\operatorname{Axp}$ & AT & $\cdot$ & - & . & . & it, & $\pi$ & - & - & or: & or & $\varepsilon, 1$ & $\varepsilon$ & $\pi, 5$ & $\pi$ & : \\
\hline${ }_{\text {- }}$, A. & '.. & 7. & $\pi, T$ & $\pi$ & - & - & $r, y$ & $m$ & - & - & $r, \gamma$ & $r_{z}$ & - & $\cdot$ & - & - & 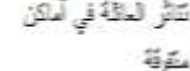 \\
\hline$-2 \gamma y \pi$ & ,.. & $7 x$ & . & . & . & - & $n, y$ & I7 & . & . & $T i, \cdot T$ & $\pi$ & . & . & . & . & 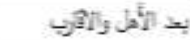 \\
\hline$-10 i, 0$ & $1 .$. & $7 x$ & 7, & 7 & . & . & t., 7 & T. & . & . & $a \varepsilon_{z}=$ & $\Delta \varepsilon$ & . & . & $1, T$ & 15 & 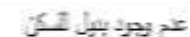 \\
\hline$\pi r_{*}=0$ & $\Delta r_{z} A$ & AT & $x_{2} T$ & w & . & . & - & - & ז & $\pi$ & $w,-1$ & 72 & - & . & . & . & 2010 \\
\hline$-1,18, \ldots$ & 1... & भi & - & - & - & - & $\theta \varepsilon, 3$ & or & - & - & $2 x, i$ & [7 & - & - & \&) & $A$ & 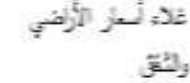 \\
\hline$-i r y, f y$ & $1 \cdots$ & Fis & $T \varepsilon, \tau$ & 72 & . & . & $r=\lambda$ & $v=$ & . & . & ar,A & ro & . & . & . & . & إ. \\
\hline$-7 T_{10}$ & ras & rA & 20,2 & ti & 71,1 & T. & $22, y$ & 00 & . & . & . & . & . & . & . & . & 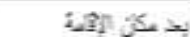 \\
\hline - & 1.. & is & 1... & 49 & . & - & - & - & - & . & - & . & . & . & - & . & Dh \\
\hline$-4, n \varepsilon$ & $7 x$ & ft & 10,7 & is & . & . & . & . & $T$ & $T$ & $1 \varepsilon_{2}$ & 18 & . & . & . & . & 4 aj, \\
\hline$\cdot{ }^{\top}$ & ,.. & Fis & $1 .$. & 4y & . & . & t) & $T$ & - & . & - & . & - & . & . & . & حדיה \\
\hline
\end{tabular}


باستقراء بيانات الجدول رقم (ع) نجد تعدد الاستجابات فكانت أكبر المشكلات الاجتماعية عددً للكرنك قبل التهجير . • • أكدت نتائج الدراسة أن كثرة الخلافات العائلية كانت من أكثر المشكلات الاجتماعية بالكرنك بنسبة r,r世\% ويرجع ذلك:

إلى الصراع على قيمة التعويض ومحاولة البعض الاستحواذ على أكبر قيمة مالية، بالية

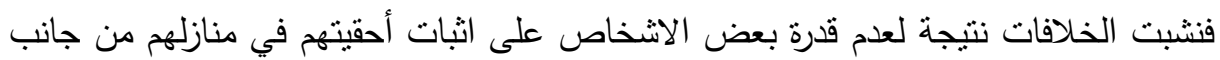

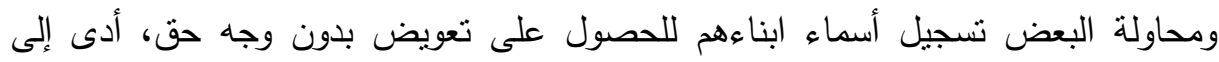

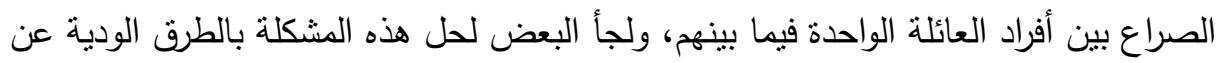

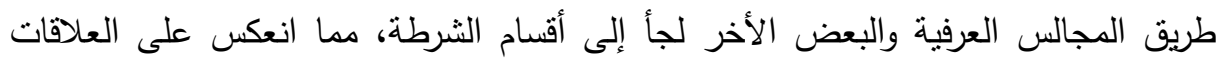

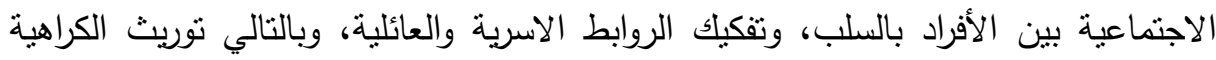
والحقد بين أفراد العائلة الواحدة.

• أنشارت نتائج الدراسة أن إلى غياب العدالة والعشوائية في توزيع التعويضات، حيث اختلفت قيمة التعويض من منزل لأخر على الرغم من التساوي في المساحة وعدد الأدوار نتيجة

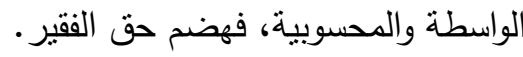

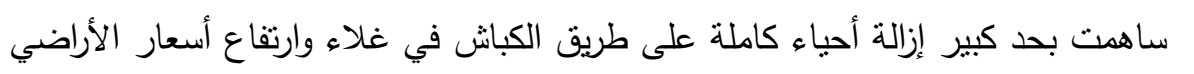
حيث أضطر المتضررين للبحث عن قطعة أرض بسعر مناسب لا يفوق قدراتهم المالية فلم يجدوا مكانا أنسب من القرى والمناطق النائية بعد أن وصل سعر القيراط الى أكثر لئر • 1 ألف جنية وفى أحيان اخرى . . بألف جنيه

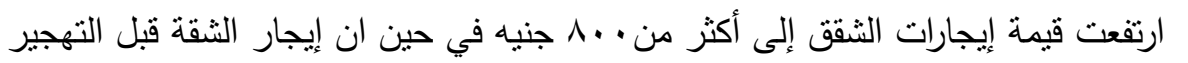

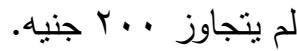
تنين من نتائج الدراسة أن أكثر المشكلات اجتماعية في الكرنك تمنلت في الإزالة المفاجئة، وغلاء أسعار الأراضي والثقق، وقلة التعويضات المادية، وتتاثز العائلة في لإني اماكن متفرقة في الكرنك كنتيجة حتمية للسرعة التي تم بها التهجير بدون مراعاه الجوانب الانسانية والاجتماعية والاقتصادية للأهالي. 
منى السيد حافظ عبد الرحمن وآخرون

جدول رقم(ه): يوضح أثر التهجير على مكانة العائلة الاجتماعية

\begin{tabular}{|c|c|c|c|c|c|c|c|c|}
\hline \multirow{2}{*}{ المعنوية } & \multirow{2}{*}{ كاr } & \multicolumn{2}{|c|}{ إجماليالعينة } & \multicolumn{2}{|c|}{ القرنة: } & \multicolumn{2}{|c|}{ الكرنك } & \multirow{2}{*}{ الإجابة } \\
\hline & & النسبة & العدد & النسبة & العدد & النسبة & العدد & \\
\hline$\cdot, \cdots$ & $1.7, r 99$ & $r q, 1$ & $V V$ & $r, 1$ & $r$ & $V \varepsilon, V$ & $V \varepsilon$ & تقرق وتائلة الواحدرة أفراد \\
\hline$\cdot, \cdot$ & $T \varepsilon, V \mid Y$ & $r_{0, \Sigma}$ & 0. & $\varepsilon, 1$ & $\varepsilon$ & $\leq 7,0$ & $\leq 7$ & هدم دوائلاتين \\
\hline$\cdot, \varepsilon$ & . & $V, 7$ & 10 & $9, Y$ & 9 & 7,1 & 7 & انتزاع أراضئة \\
\hline$\cdot, 99$ & $\cdots$ & $\varepsilon, 1$ & $\Lambda$ & $\varepsilon, 1$ & $\varepsilon$ & $\varepsilon$ & $\varepsilon$ & 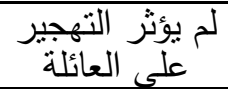 \\
\hline$\cdot, \cdots$ & $1 \leq, 919$ & $V, 1$ & $1 \varepsilon$ & $\cdot$ & $\cdot$ & $1 \varepsilon, 1$ & $1 \varepsilon$ & أخرى تذكر \\
\hline
\end{tabular}

باستقراء بيانات الجدول رقم (0) نلاحظ تعدد الاستجابات فجاءت الإجابة تفرق وتتاثر

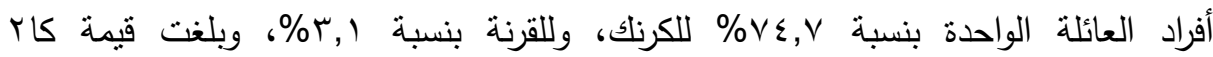

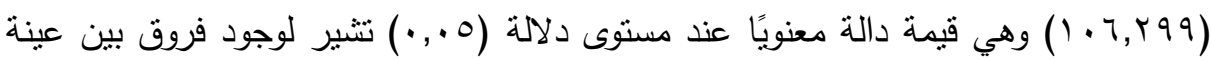

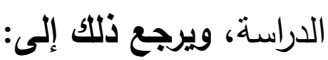

• أن العائلة تقوم بدورا فاعلا في نمو تركيبة (المجتمع) وديمومتها، لأنها القاعدة التي

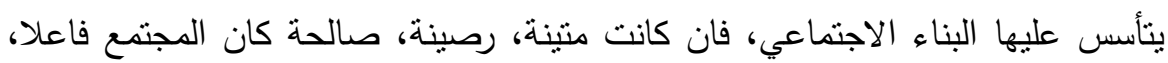
قادرا على مواجهة ظروف الحياة وضغوطها، والعكس صحيح أيضا، فإن كانت مفككة

كان المجتمع ضعيفا غير متجانس، ويالنظر الى بيانات الجدول السابق نلاحظ:

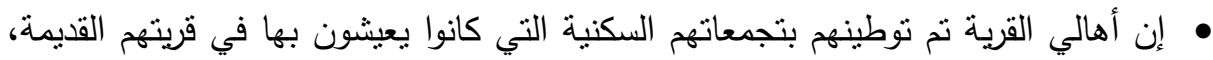

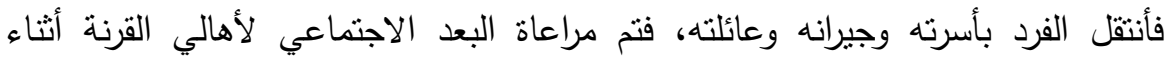

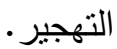

• أما بالنسبة للكرنك فلم تراعى السلطة البعد الاجتماعي فكان التهجير القسري الذى ترتب عليه تشتت وتفكك كثثر من الأسر نتيجة نباعدها في السكن والاقامة.

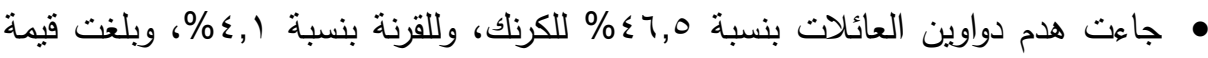

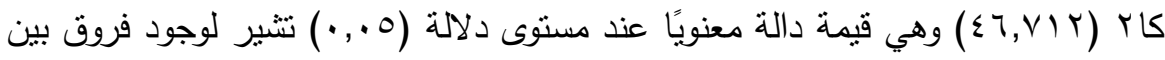
عينة الدراسة، ويملاحظة نتيجة الجدول السابق نجد أن:

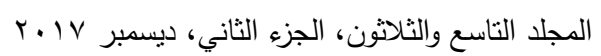


أثناء تهجير أهالي الكرنك تم إزالة كثير من الدواوين (دار للمناسبات ) التي تمثل رمز

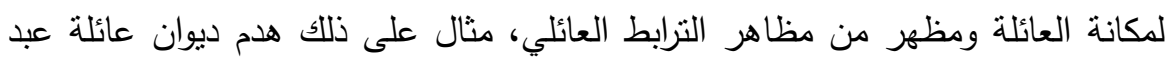
الهادي، ديوان عائلة الحوادى، ديوان عائلة المداكير، ديوان عائلة الحسانة الحساسنة.

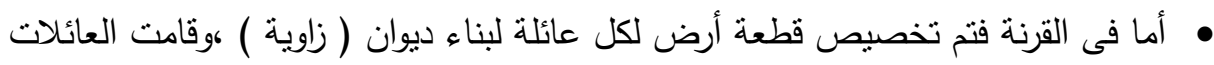
بجمع مبالغ مالية بالجهود الذاتية لبنائه مثال على ذلك زاوية لكية ( الحروبات ) وزاوية (الحساسنة ). جدول رقم(†): يوضح أصعب المشكلات الاجتماعية اللي واجهت المبحوث بعد التهجير

\begin{tabular}{|c|c|c|c|c|c|c|c|c|c|}
\hline \multirow{2}{*}{ المعنوية } & \multirow{2}{*}{ كاr } & \multirow[b]{2}{*}{ الترتيب } & \multicolumn{2}{|c|}{ إجمالى العينة } & \multicolumn{2}{|c|}{ القرنة } & \multicolumn{2}{|c|}{ الكرنك } & \multirow{2}{*}{ المشكلات } \\
\hline & & & $\%$ & (5 & $\%$ & 5 & $\%$ & ك & \\
\hline$\cdot, \cdots$ & $17, \cdot V r$ & 11 & $\vee, T$ & 10 & . & . & $10, r$ & 10 & كثرة الخلافات \\
\hline$\cdot, \cdots$ & $q \wedge, r \leqslant q$ & $r$ & 促O & 77 & . & . & $74, \mathrm{~V}$ & 77 & فتي أماكن \\
\hline$\cdot, \cdots$ & $M r, \Sigma \wedge T$ & r & $r \wedge, \tau$ & $V 7$ & . & • & $\vee \neg, \Lambda$ & $\vee 7$ & بعد الأهل \\
\hline$\cdot, \cdots$ & $r \cdot, r+1$ & $\wedge$ & 17,1 & Tr & r & r & $r, r$ & r & عدم التاققلم مع الجيران \\
\hline •, 乞 & $\cdot$, ATO & v & $r \cdot, \Lambda$ & $\leqslant 1$ & $r r, 0$ & r & $1 \Lambda, r$ & 11 & علدم وجود \\
\hline$\cdot, 0$ & $\cdot, \varepsilon \Gamma \wedge$ & $\varepsilon$ & M,o & Tr & Tr,V & Tr & $r q, r$ & rq & بعد السكن عن \\
\hline$\cdot, 1$ & $r, 17 \varepsilon$ & 1. & $I r, V$ & ro & $9, r$ & 9 & $17, r$ & 17 & بعد السكن عن الأولاد \\
\hline$\cdot, 0$ & $\cdot, \Sigma Y r$ & 9 & $I r, V$ & rV & $10, r$ & 10 & $\mid r, 1$ & ir & عدم توفر \\
\hline-- & -- & -- & . & $\cdot$ & . & $\cdot$ & . & $\cdot$ & الإزالة المفاجئة \\
\hline$\cdot, \cdots$ & or, $1 \cdot 1$ & 1 & $\leqslant 1,7$ & Ar & $T V, r$ & 77 & $17, r$ & 17 & أماكن للنزهودة \\
\hline$\cdot, \cdots$ & $\vee q, \Gamma q \vee$ & 0 & $r \wedge, q$ & ov & . & . & ov, 7 & ov & قلة التعوبضات \\
\hline$\cdot, \cdots$ & $\vee 1, \vee \vee 0$ & 7 & $r 7,9$ & or & . & . & or,o & or & غلأع الأسعار \\
\hline-- & -- & -- & . & . & · & $\cdot$ & $\cdot$ & $\cdot$ & حالات الطلاق \\
\hline$\cdot, \cdots 1$ & $1 Y, 00$ & 11 & $\mathrm{~V}, 7$ & 10 & 1 & 1 & $1 \leqslant, 1$ & $1 \leq$ & السرقة \\
\hline$\cdot, \cdots$ & & IT & 1 & $r$ & $\cdot$ & $\cdot$ & $r$ & $r$ & الانتحار \\
\hline
\end{tabular}


بالنظر إلى بيانات الجدول (T) نلاحظ أن أصعب المشكلات التي واجهت عينة البحث

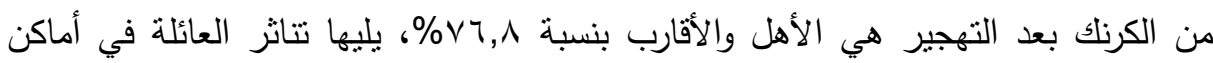

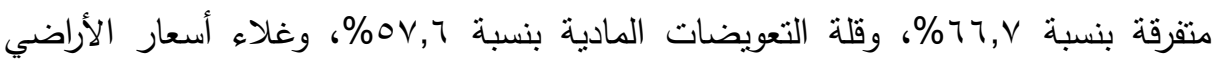

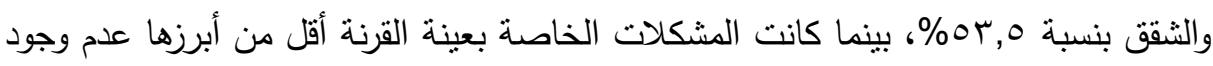

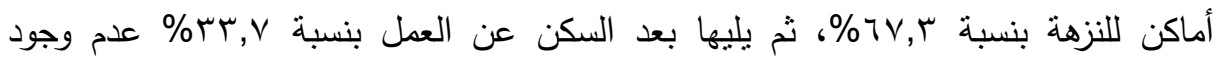

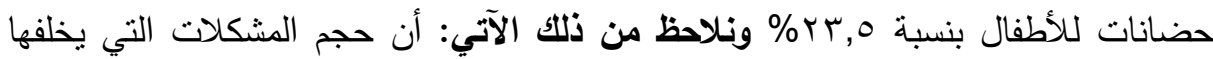
التهجير القسري تاركًا أثنار اجتماعية ونفسية واقتصادية على المهجرين في حين ان التهجير لتهني

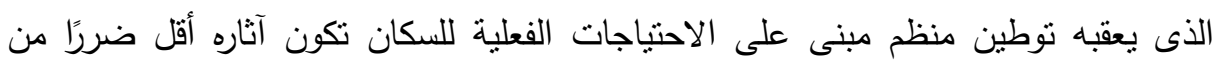
التهجير القسري.

فالتوطين المنظم يتضمن مجموعة من المعايير والمبادئ التي تضمن حقوق المهجرين وتقليل من حجم المشكلات التي يمكن ان تقابلهم منها على سبيل المثال:

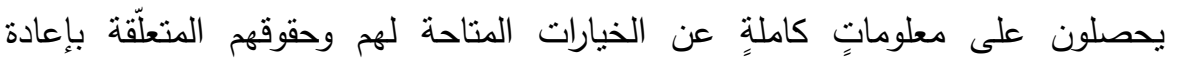
التوطين، بما في ذلك خيارات التوطين حول المشروع لضمان الاستفادة منه. هُيُنتشارون وتُعْرض عليهم وتُقدّم لهم بدائل إعادة توطين ممكنة التنفيذ فنباً واقتصادياً.

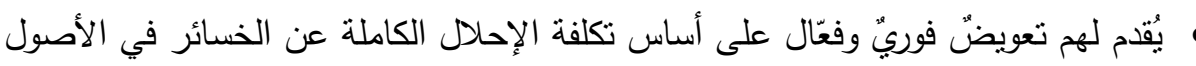
(الأراضي والمباني والمحاصيل وأثجار الثر ) الني يُعزى فقدانها إلى المشروع.

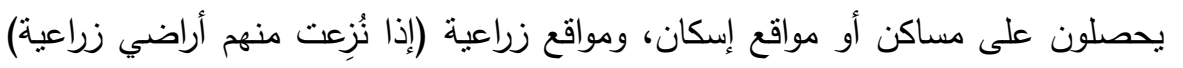
يكون مجمل إمكاناتها الإنتاجية ومزايا موقعها والعوامل الأخرى معادلةً على الأقل لمزايا

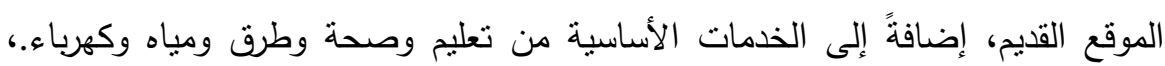

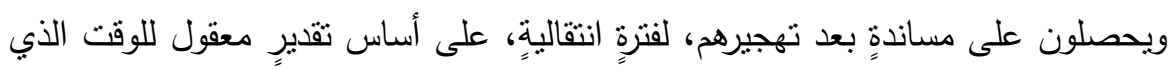

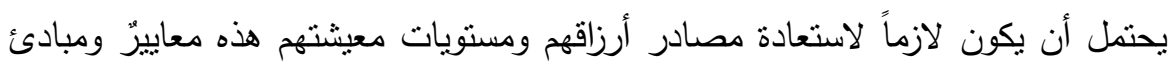

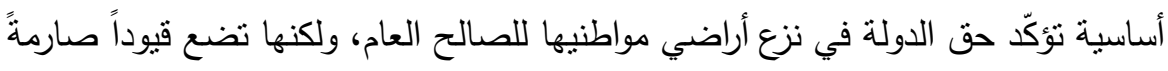

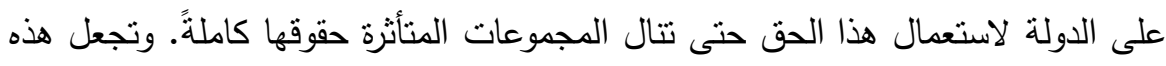

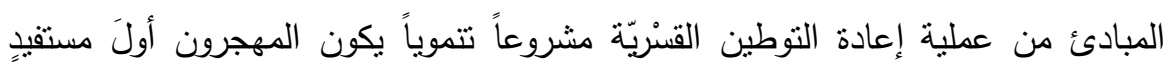

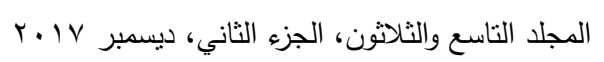


منه. وتضع هذه المبادئ قاعدةً أساسيةً وهي أن تكون نتيجة إعادة التوطين هي تحسين مصادر أرزاق المهجّرين ومستويات معيشتهم، أو على الأقل إعادتها، بالقيمة الحقيقية.

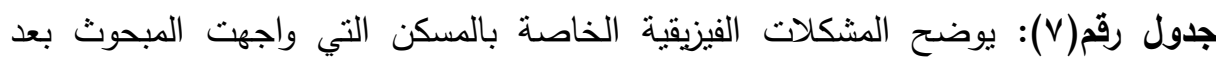

\begin{tabular}{|c|c|c|c|c|c|c|c|c|c|}
\hline & & & & & \multicolumn{5}{|c|}{ التهجير } \\
\hline \multirow{2}{*}{ المعنوية الدة } & \multirow{2}{*}{ كاr } & \multirow{2}{*}{ الترتيب } & \multicolumn{2}{|c|}{ أجمالةي } & \multicolumn{2}{|c|}{ القزنة } & \multicolumn{2}{|c|}{ الكرنك } & \multirow{2}{*}{ المشكلات } \\
\hline & & & $\%$ & 5 & $\%$ & 5 & $\%$ & 5 & \\
\hline$\cdot, \cdots$ & IY,OYT & $r$ & $10, r$ & $r$ & 7,1 & 7 & $r \varepsilon, r$ & $r \varepsilon$ & آ. قلة التهوبة \\
\hline$\cdot, \cdot r$ & $0, V \leqslant V$ & V & $\vee, 7$ & 10 & $r, 1$ & 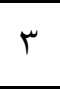 & $|r|$, & ir & تدخله شـ المسكن لا \\
\hline$\cdot, \cdot r$ & $0, \cdots$ & 7 & $11, r$ & rt & 7,1 & 7 & $17, r$ & 17 & تدربة ت توجد \\
\hline$\bullet, \cdots$ & $r r, \cdot 1 \wedge$ & 1 & $\varepsilon 0, V$ & 9. & $T r, r$ & $7 r$ & Y^,0 & YA & شثرات توجد \\
\hline$\cdot, \Gamma$ & $1, \cdot 1$ & $\Lambda$ & $\cdot, 0$ & 1 & 1 & 1 & - & - & المبنى \\
\hline$\cdot, \wedge$ & $\cdot, \cdot \leq \Lambda$ & r & $1 \mathrm{~V}, \mathrm{~A}$ & ס r & $1 \wedge, \varepsilon$ & 11 & $1 v, 1$ & IV & المساحة ضليق \\
\hline$\cdot, .0$ & $r, \wedge) \tau$ & 0 & $I T, V$ & ro & IV,r & 18 & $\wedge$ & $\Lambda$ & بالخصن لالجيران \\
\hline$\cdot, \mathrm{V}$ & $\cdot, 1 \wedge r$ & 7 & $11, r$ & rr & $1 \cdot, r$ & 1. & $|r|$, & ir & ذالمسكن \\
\hline$\cdot, 7$ & • & $\varepsilon$ & $1 \varepsilon, V$ & rq & r & r & $17, r$ & 17 & رشكلة \\
\hline
\end{tabular}

باستقراء بيانات الجدول (V) نلاحظ تعدد استجابات المبحوثين فكانت أصعب المشكلات الفيزيقية التي واجهت المبحوث بعد التهجير في القرنة تمثلت في توجد حشرات بالمنزل بنسبة

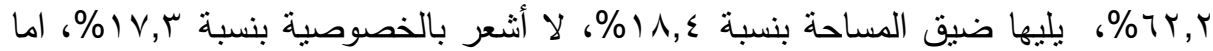

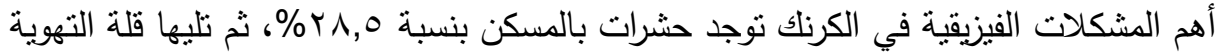




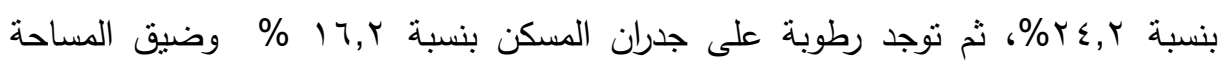

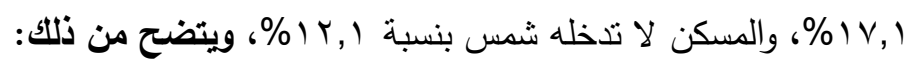

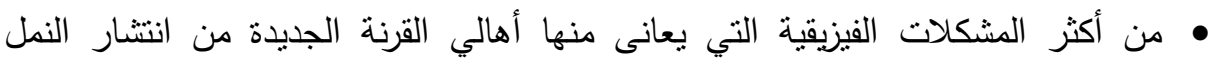

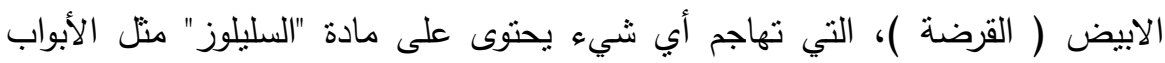
والثبابيك والاثاث والمواد المكونة من الورق، وقد تم معالجتها أكثز من مرة من قبل مديرية الزراعة إلا انه يعود مرة أخرى، بالإضافة إلى انتشار الحشرات الزاحفة مثل العقارب.

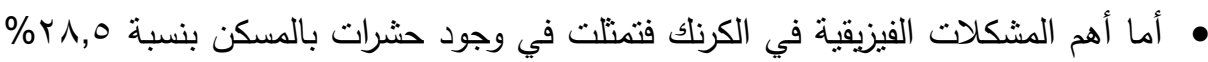
فغالبًا ما نعانى المناطق السكينة الريفية من عدم النظافة، فالصرف الصحي ينم صرفه في الترع والمصارف، ويتم إلقاء النفايات والقمامة بها مما يؤدى إلى انبعاث وانتشار الروائح الكريهة، فتصبح هذه الأماكن مرتع لانتشار الذباب والناموس والبعوض وغيرها من لهن الحشرات، مما يؤدى إلى انتشار الامراض المختلفة. جدول رقم(^): يوضح أصعب المشكلات الفيزيقية اللي واجهت المبحوث في منطقته بعد الامرضد التهجير

\begin{tabular}{|c|c|c|c|c|c|c|c|c|c|}
\hline \multirow{2}{*}{ الدمولة } & \multirow{2}{*}{ rLs } & \multirow{2}{*}{ الترتيب } & \multicolumn{2}{|c|}{ 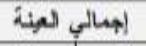 } & \multicolumn{2}{|c|}{ القرنية } & \multicolumn{2}{|c|}{ الكرئك } & \multirow{2}{*}{ الشئكل } \\
\hline & & & $\%$ & $\Delta$ & $\%$ & $\Delta$ & $\%$ & $\Delta$ & \\
\hline$\therefore 1$ & , ror & $r$ & $i v, v$ & 98 & $t i, \lambda$ & ii & 0,0 & e. & 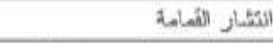 \\
\hline .7 & , ror & r & $\varepsilon Y, Y$ & 98 & 60,9 & to & 29,0 & 29 & 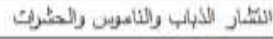 \\
\hline$\therefore 0$ & . rAY & $\mathrm{v}$ & $10, \mathrm{~V}$ & $r$ & $1 v, r$ & iv & $1 \varepsilon, 1$ & 18 & ازٔدجام المطظقة \\
\hline$\ldots$ & $3, \mathrm{rro}$ & 11 & $1, \mathrm{~V}$ & $r$ & 0,1 & $\circ$ & $17, y$ & 17 & القنوطساء \\
\hline$\cdots \cdots$ & 10,190 & $r$ & $\{1,7$ & Ar & $Y Y, T$ & rv & $\Delta 0,1$ & 00 & 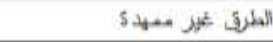 \\
\hline$\ldots+1$ & $3,4 \mathrm{~V}$ & 0 & $\mathrm{ri}$ & vi & $\gamma V, 7$ & rv & $\varepsilon \varepsilon, \varepsilon$ & if & الهطلكة كاثية \\
\hline$\cdots v$ & r,roo & 1 & 09,9 & $11 \mathrm{~A}$ & $17, r$ & 10 & or,o & or & 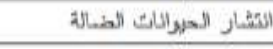 \\
\hline,$+ Y$ & 1,701 & 1 & 19,1 & $r q$ & $17, Y$ & 17 & $r r, 0$ & ir & 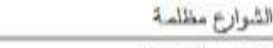 \\
\hline$\cdot, 4$ & $\cdot, r e q$ & ir & 1,0 & $r$ & r & $r$ & 1 & 1 & العباتي ملك هورئ \\
\hline- & - & - & . & . & . & , & , & , & 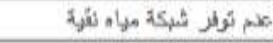 \\
\hline$\cdot, T$ & $1,+18$ & $i$ & $8 \cdot, 7$ & A. & $r u, Y$ & $r 7$ & $\varepsilon \varepsilon, i$ & $i t$ & صعبرية المواصلكت \\
\hline- & - & - & . & $\cdot$ & . & . & . & . & 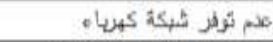 \\
\hline$\ldots \ldots$ & $r A, T \leqslant \varepsilon$ & $A$ & $1 \%, y$ & ro & , & $\cdot$ & $r e, r$ & ro & 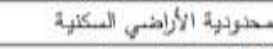 \\
\hline$\cdot, \mathrm{V}$ & . IAr & 1. & $11, r$ & ry & $1, . r$ & 1. & $1 r, 1$ & ir & تلة الخحسات الصبرة \\
\hline$\ldots \ldots \varepsilon$ & $A, Y O \varepsilon$ & ir & $\varepsilon, 1$ & $\wedge$ & . & . & $\Lambda_{1}^{\prime}$ & $\wedge$ & علم توئر شيكئ كهريا. \\
\hline$\therefore, \cdots$ & YV, or & 9 & IY,Y & ri & , & . & $Y \xi, Y$ & ri & 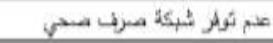 \\
\hline
\end{tabular}


باستقراء بيانات الجدول (^) نلاحظ تعدد استجابات المبحوثين فنجد أصعب المشكلات الفيزيقية التي واجنهم بعد التهجير كانت كالآتي: أعلى نسبة كانت لعينة الكرنك الطرق غير

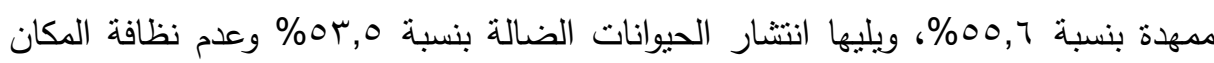

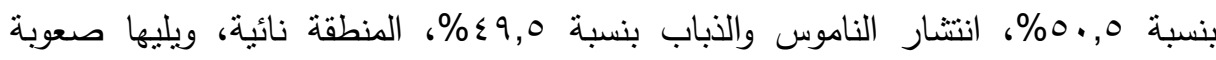

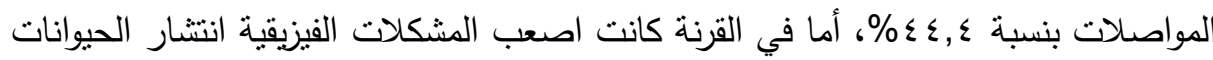

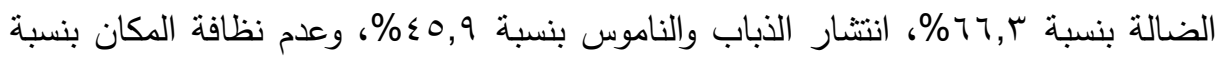

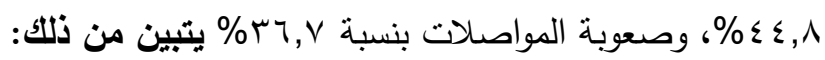
• أن عينة الكرنك استوطنت بعد التهجير في مناطق ريفية نائية، تفنقد إلى الخدمات الأساسية، وتعج بالمشكلات الفيزيقية منها على سبيل المثال عدم تمهيد الطرق حيث يوجد

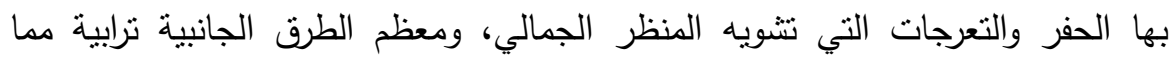

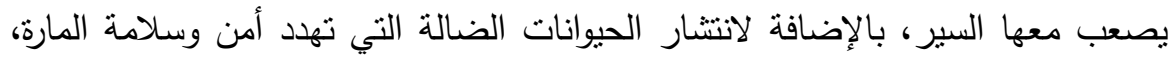

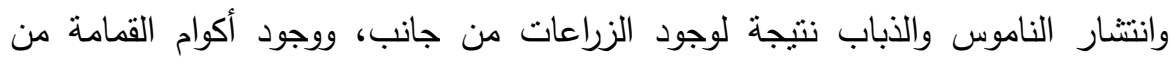
جانب أخر، وتتقق هذه النتيجة مع دراسة (Carol McKenzie , John Flint) التي وني أكدت أن الأحياء المحرومة نواجه تحديات بيئية أكثر حدة، خاصة مع القمامة، ونقل البقع دانع

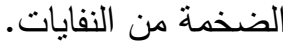
انتشار الحيوانات الضالة في الثوارع مشكلة تؤرق الأهالي بشكل كبير، وتصيبهح بالقلق خاصة على أطفالهم خوفا من اعتراض الكلاب لطريقهم وعضهم أو إيذاء أحدهم، حيث تتجمع أعدادا غفيرة من الكلاب حول اكوام القمامة، وتسير في مجموعات مع بعضها بشكل بثير الفزع. 
منى السيد حافظ عبد الرحمن وآخرون

جدول رقم(9): يوضح الأسباب والحلول المقترحة للمشكلات الفيزيقية التي واجهت المبحوث

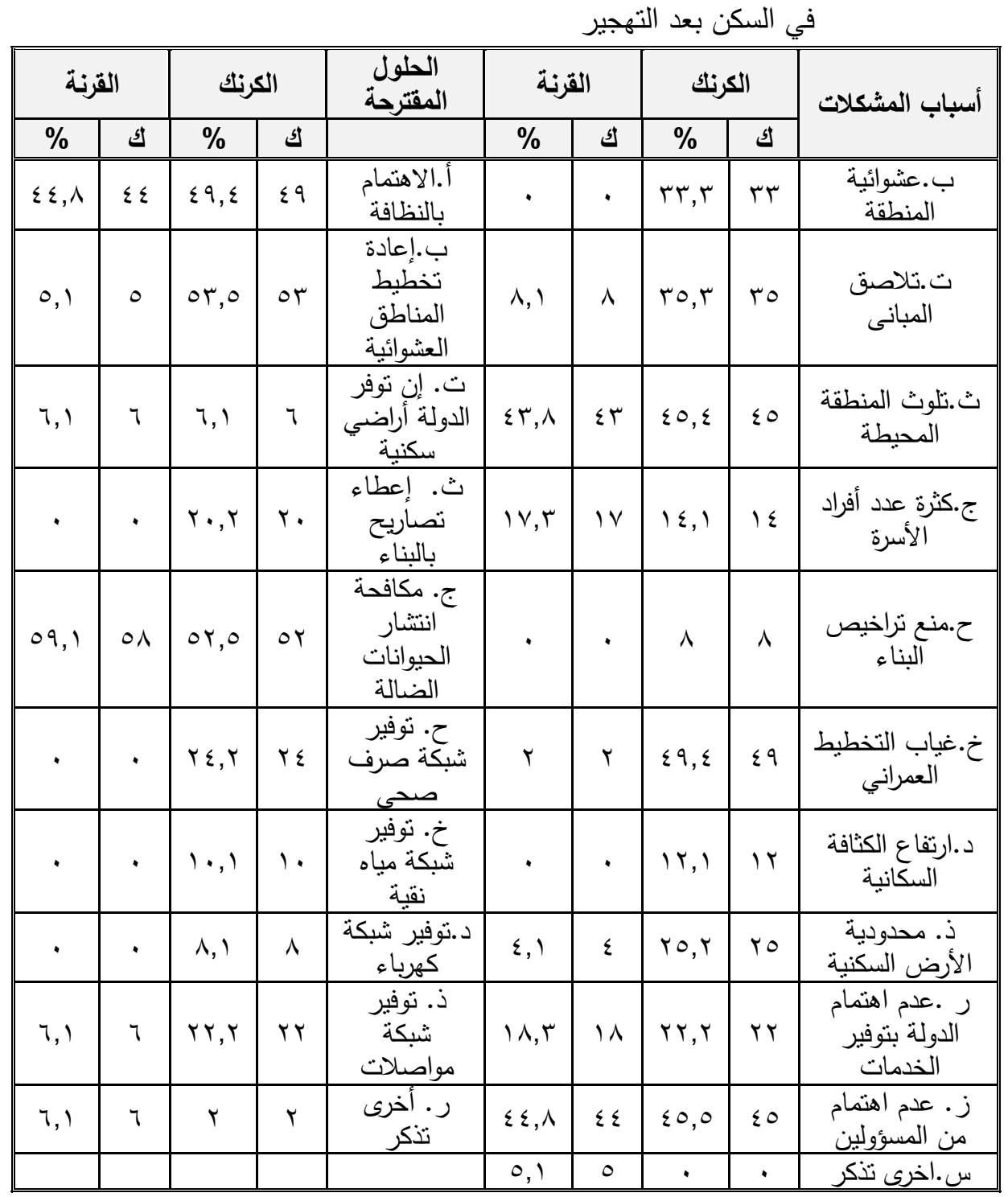


باستقراء بيانات الجدول (9) نلاحظ تعدد استجابات المبحوثين، فكانت أكثر أسباب

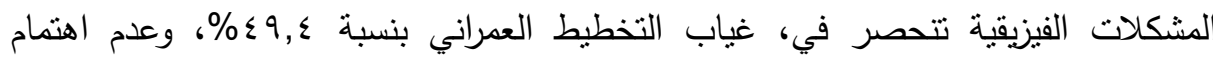

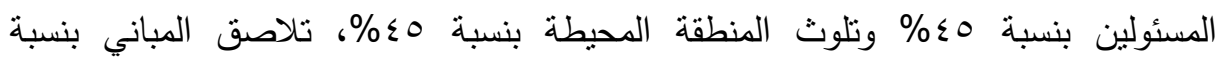

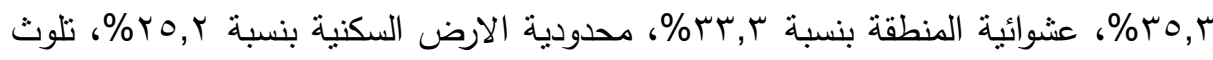

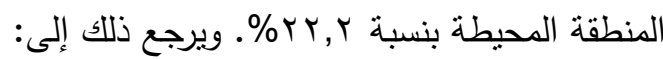
• غالبية المساكن، لا تخضع لأى نوع من أنواع الرقابة أو التخطيط أو التنظيم في قوانين

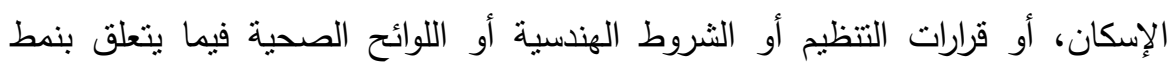

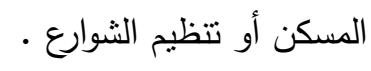

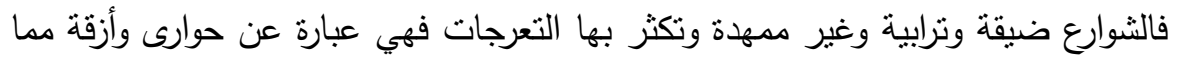
يصعب مرور السيارات، وتعبر تللك المساكن والثوارع عن التذهور العام للبيئة الفيزيقية للمكان.

• أما بالنسبة للقرنة فكانت أهم أسباب عدم اهنمام المسئولين بنسبة ^,ـ § \%، تلوث المنطقة

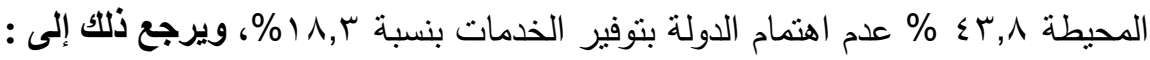
ويثمل اهتمام المسئولين كافة النواحي من خلال: • وضع خطة لإعادة تخطيط الطرق وتمهيدها ورصفها حتى يسهل المرور عليها. • إعادة تخطيط المناطق العشوائية التى تعج بالعديد من المشكلات الاجتماعية والاقتصادية والبيئية. •الاهتمام بمكافحة الحيوانات الضالة من خلال حقنها حتى تمنع تكاثرها وزيادة اعدادها والتخلص منها بطريقة أمنه وصحية. كانت من أبرز الحلول التي قدمتها عينة البحث بالكرنك، إعادة تخطيط المناطقة

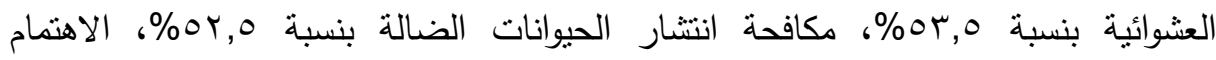

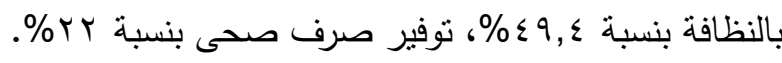


أما الحلول التي قدمتها عينة البحث بالقرنة فتمثلت في مكافحة انتشار الحيوانات الضالة

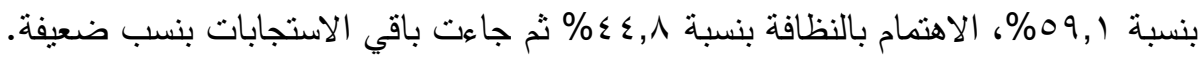

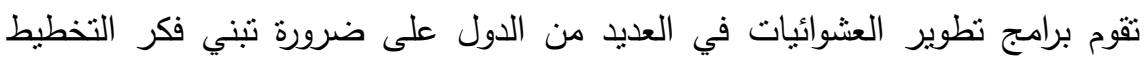

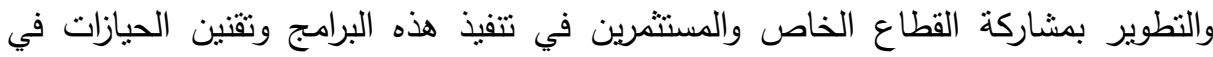
العشوائيات لحفظ حقوق الدولة وتتشيط السوق العقاري من خلال تسجيل المباني ونطبيق مبدأ

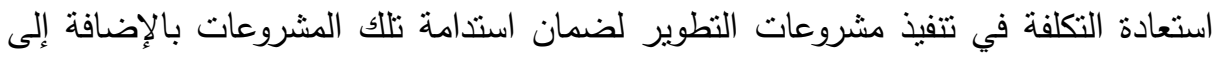
تتجيع القطاع الخاص على المشاركة في تطوير العشوائيات من خلال تقديم بعض بلى التسهيلات والحوافز والتي تتمثل في الحصول على نسب من الأراضي الصالحة للتتمية بتلك فئك

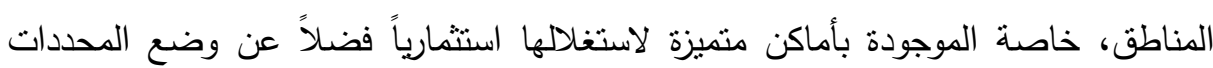

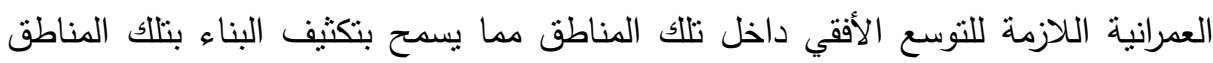
والحد من أي امتداد عشوائي، وتتضمن خطط تطوير العشوائيات مشاركة المواطنين في هذه

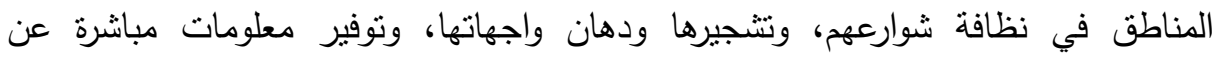

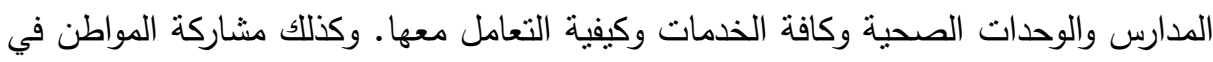

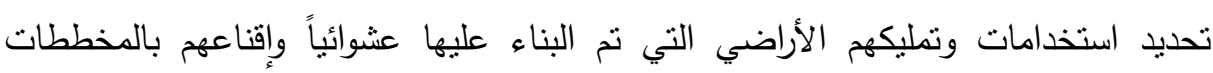
الجديدة. 
مجلة العلوم البيئية

معهد الدراسات والبحوث البيئية - جامعة عين شمس لئ

جدول رقم( • 1): يوضح الأسباب والحلول المقترحة للمشكلات الفيزيقية التي واجكت المبحوث في السكن بعد التهجير

\begin{tabular}{|c|c|c|c|c|c|c|c|c|c|}
\hline \multicolumn{2}{|c|}{ القرنة } & \multicolumn{2}{|c|}{ الكرنك } & \multirow{2}{*}{ الحلول المقترحة } & \multicolumn{2}{|c|}{ القرنة } & \multicolumn{2}{|c|}{ الكرزتك } & \multirow{2}{*}{ أمشبابت } \\
\hline$\%$ & S & $\%$ & ك & & $\%$ & ك & $\%$ & ك5 & \\
\hline$\varepsilon \varepsilon, \wedge$ & $\varepsilon \varepsilon$ & $\leqslant 9, \varepsilon$ & $\leqslant 9$ & أ.الاهتمام بالنظافة & . & . & r,r & זr & ب.عشوائية \\
\hline 0,1 & 0 & or,o & or & البناطقادة العشوائية & $\Lambda, 1$ & $\wedge$ & ro,r & ro & ت.تلاصق \\
\hline 7,1 & 7 & 7,1 & 7 & تأ. إن توفي الدولة & $\varepsilon r, \wedge$ & $\varepsilon r$ & $\leq 0, \varepsilon$ & $\leqslant 0$ & $\begin{array}{l}\text { الثنظقةثة } \\
\text { المحيطة } \\
\end{array}$ \\
\hline - & $\cdot$ & $r \cdot, r$ & $r$. & تصاريح بالبناء & IV,r & IV & $1 \leqslant, 1$ & $1 \varepsilon$ & أجفراد الأسرة عدد \\
\hline 09,1 & 01 & or,o & or & جالحيوانات الضالة انتشار & . & . & $\wedge$ & $\wedge$ & تراخيص ح.منع \\
\hline . & $\cdot$ & $T \leqslant, Y$ & $r \varepsilon$ & صرف صنير شبكية & r & $r$ & $\leqslant q, \varepsilon$ & $\leqslant 9$ & التخطيط \\
\hline - & $\cdot$ & $1 \cdot, 1$ & 1. & خ مياه نقية شبكة & . & . & $\mid r, 1$ & Ir & $\begin{array}{l}\text { الكنافة دارة } \\
\text { السكانية }\end{array}$ \\
\hline . & $\cdot$ & $\Lambda, 1$ & $\wedge$ & د.نوفير شبكة & $\varepsilon, 1$ & $\varepsilon$ & $r 0, r$ & ro & ذألمحدودية الأرضية \\
\hline 7,1 & 7 & $r, r$ & Yr & ذ. توفير شبكة & $1 \wedge, r$ & 11 & $r, r$ & rr & الذاهنمام \\
\hline 7,1 & 7 & r & $r$ & ر. أخرى تذكر & $\varepsilon \varepsilon, \wedge$ & $\varepsilon \varepsilon$ & $\leqslant 0,0$ & $\leqslant 0$ & المتمام من \\
\hline & & & & & 0,1 & 0 & . & . & س.خرى \\
\hline
\end{tabular}


باستقراء بيانات الجدول (• (1) نلاحظ تعدد استجابات المبحوثين، فكانت أكثر أسباب

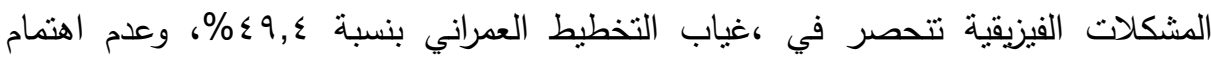

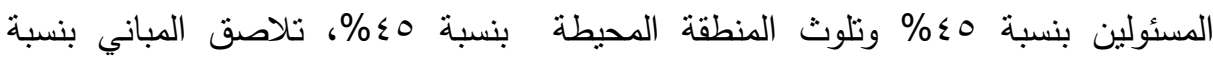

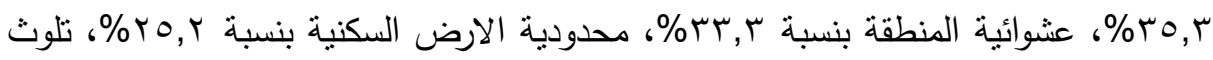

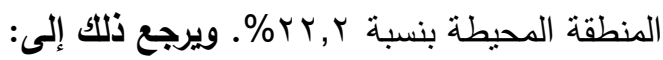
غالبية المساكن لا تخضع لأى نوع من أنواع الرقابة أو التخطيط أو التنظيم في قوانين

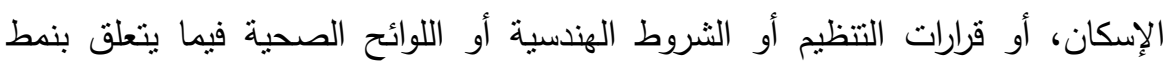

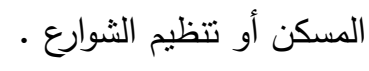

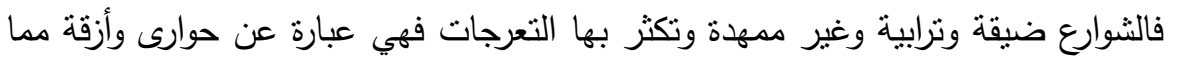
يصعب مرور السيارات، وتعبر تلك المساكن والثوارع عن التدهور العام للبيئة الفيزيقية لل لمكان

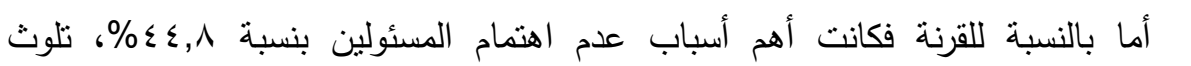

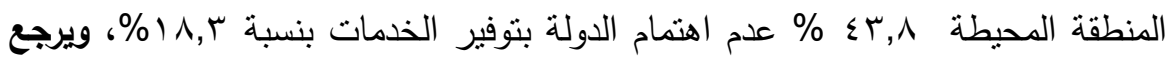
ذلك إلى: ويشمل اهتمام المسئولين كافة النواحي من خلال: • وضع خطة لإعادة تخطبط الطرق وتمهيدها ورصفها حتى يسهل المرور عليها.

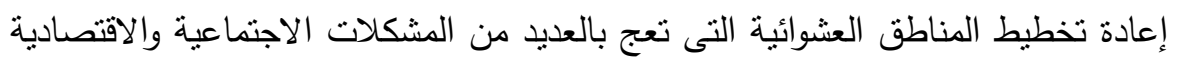
والبيئية. • الاهتمام بمكافحة الحيوانات الضالة من خلال حقنها حتى تمنع تكانرها وزيادة اعدادها والتخلص منها بطريقة أمنه وصحية. كانت من أبرز الحلول التي قدمتها عينة البحث بالكرنك، إعادة تخطيط المناطق وهن

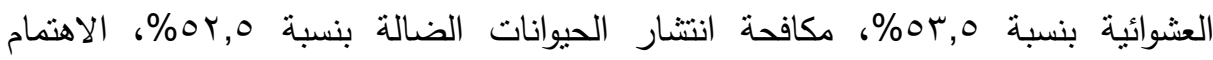

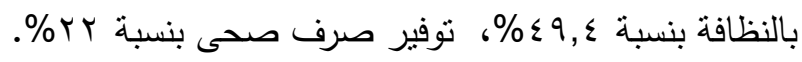


أما الحلول التي قدمتها عينة البحث بالقرنة فتمنلت في مكافحة انتشار الحيوانات الضالة

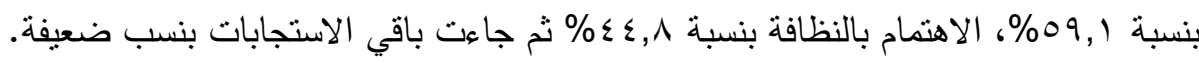

\section{اللزوسيايت}

في ضوء مشكلة الدراسة ويناء على النتائج التي توصلت إليها الاراسة، توصى بما يلى:

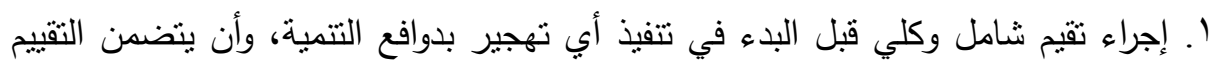

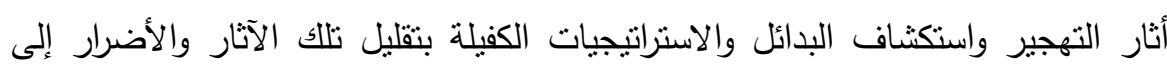
أدنى حد. r r. الاهتمام بمشاركة كل من يتضرر من عمليات التهجير وتزويدهم بمعلومات كاملة حول أسباب تهجيرهم والإجراءات الأزمة، مع ضمان مشاركتهم في التخطبط لعملية التهجير .

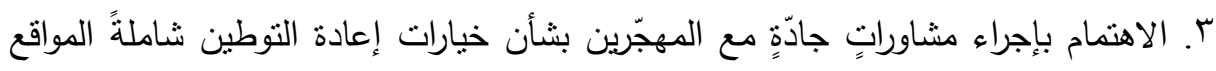

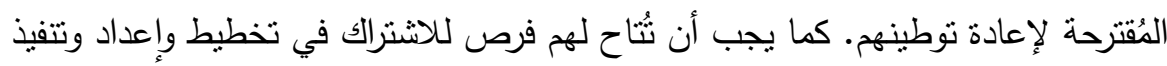
برامج إعادة التوطين. ؛. يتعين على السلطات المختصة أن نوفر لمن تم تهجيرهم مساكن بديلة وتعويضهم عن إعلن الاضرار التي لحقت بهم من جراء التهجير. ○. توصى الدراسة بضرورة تجنب التهجير القسري لما له من أضرار اجتماعية ونفسية واقتصادية على المهجرين. T. العمل على تحسين نوعية الحياة في مناطق القرى والمراكز المحرومة من التتمية في محافظة الأقصر مثل قرية البنى الجديدة، العوابد من خلال الاهتمام بالبنية التحتية، والاهتمام بتوفير الخدمات الاساسية. V . يحتاج مجتمعي الدراسة بالكرنك والقرنة لمزيد من الدراسات البحثية منها على سبيل المثال

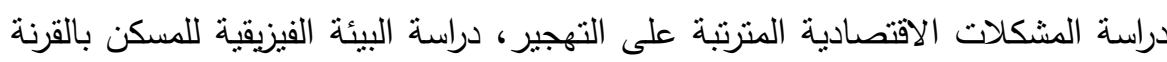
الجديدة، دراسة القيم المرتبطة بالتهجير القسري، دراسة البناء الاجتماعي للأسر المهجرة 
بمجتمع الكرنك، وذلك من خلال الجود البحثية المقدمة من جامعة جنوب الوادى

$$
\text { والجامعات المختلفة. }
$$

\section{zall}

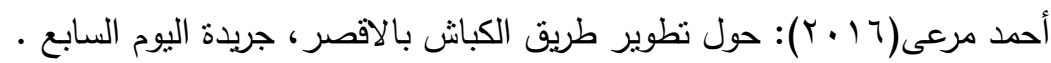

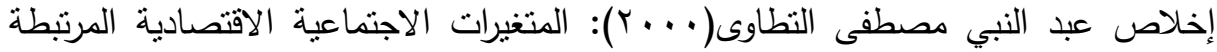

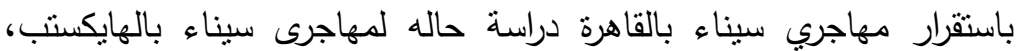

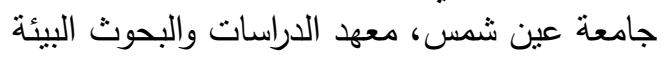

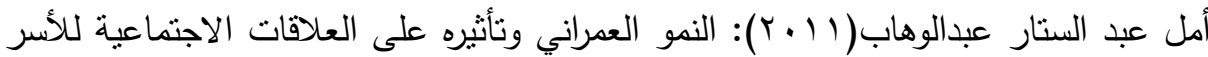

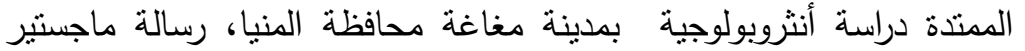
غير منشورة، جامعة عين شمس، معهد الدراسات والبحوث البرائة البيائية جابر سيد عوض(بدون سنة النشر) :التكنولوجيا والعلاقات الاجتماعية، القاهرة، دار المعرفة الثئة الجامعية

جون ركس(بدون سنة النشر): مشكلات أساسية فى النظرية الاجتماعية ترجمة محمد الجوهري

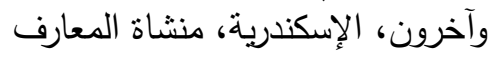

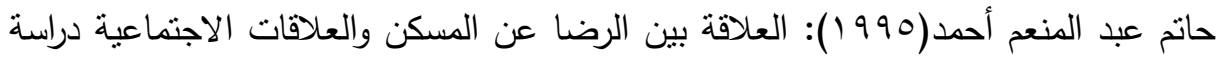

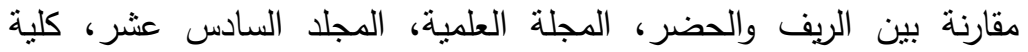

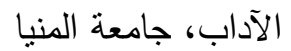

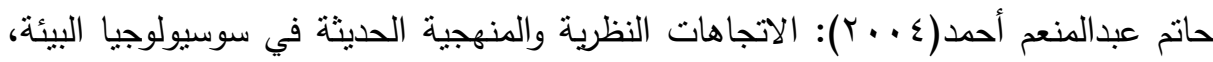

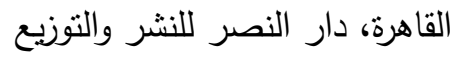

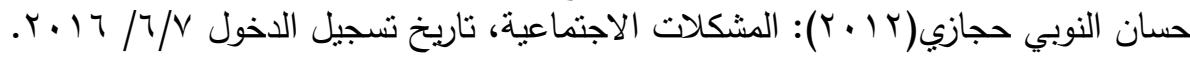

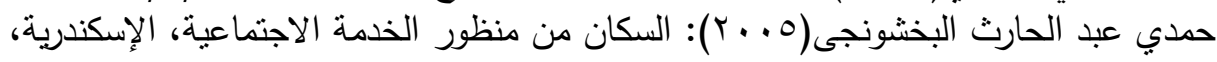
المكتبة الجامعية

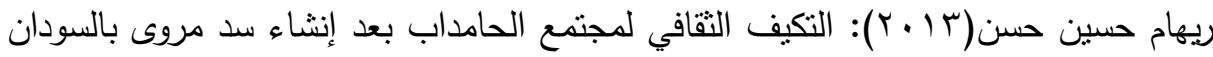

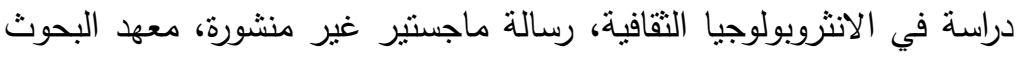
والدراسات الإفريقية، جامعة القاهرة الترانة

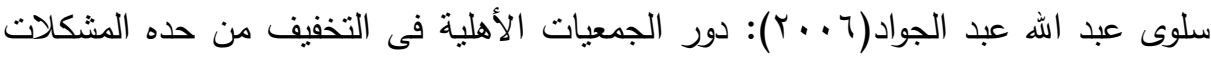

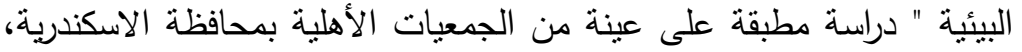

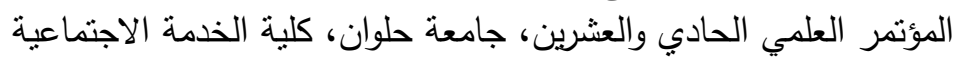

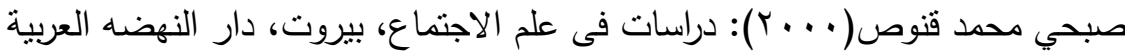

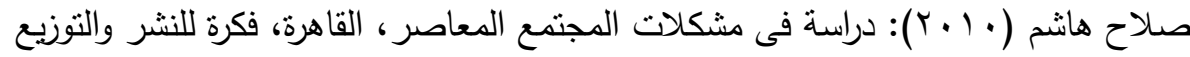

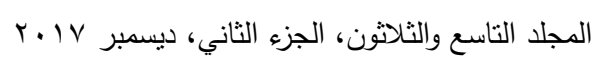




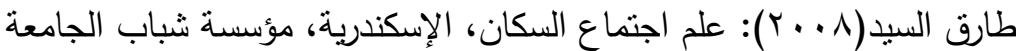

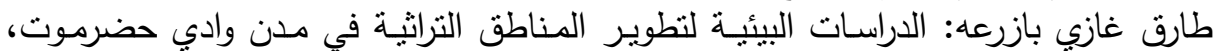
مجلة العلوم الهندية، جامعة أسيوط، المجلد.

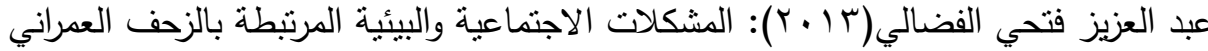

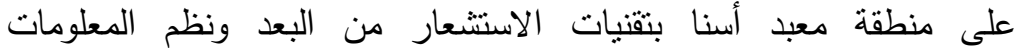
الجغرافية، رسالة ماجستر غير منشورة، معهد الدراسات والبحوث البيائة، جامعة عين شمس النشر

عبد الفتاح عثمان(بدون سنة النشر ) ): خدمة الفرد فى اطار التعددية المعاصرة، القاهرة، مكتبة

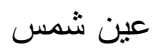

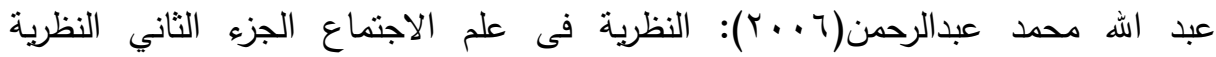

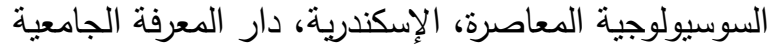

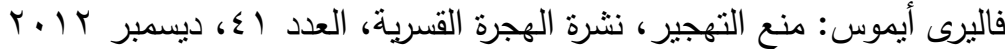
كايت هوشور: تقويض الإنماء الإخلاء القسرى فى بنجلادش، نشرة الفرة الهجرة القسرية، العدد

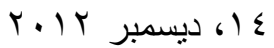

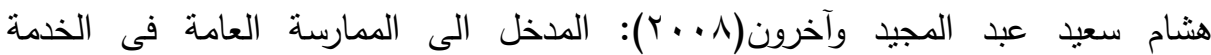
الاجتماعية، القاهرة، المهندس للطباعة الهر

http://ruralhassan2020.blogspot.com.eg

محمد حسين عبد القوى(بدون سنة النشر):التلوث البيئي، المركز الإعلامي تاريخ الدخول /0/ www:policomc.gov.bh $. r+17 /$

http://ara.reuters.com.

Etienne Winger, communities of practice, Cambridge university press, 1999,p241.

F. Znaniek, Social Relations and Social Roles, 2001.

Marina and Melanie killen, Evolution and Development, 1998

Guataquí Roa, J.C., Forced displacement and internal migration in Colombia 1992 - 2004 Ph.D, United States, 2006. 
منى السيد حافظ عبد الرحمن وآخرون

\title{
SOCIAL AND PHYSICAL PROPIEMS RESULTING IN DISPIACEMENT OF EL-KARNAK AND AL- GORNA AREAS PEOPLE AND THEIR IMPACT ON SOCIAL RELATIONSHIPS - AFIELD STUDY
}

\author{
Abd Elrahman, Mona, E. H. ${ }^{(1)}$; Mohamed, A. A. E. ${ }^{(1)}$ \\ and Eltahr, Fatma, $M$. \\ 1) Faculty of Art, Ain Shams University
}

\begin{abstract}
Luxor governorate of Upper Egypt considers one of the largest monumental governorates that includes on its lands third of the world's monuments. For its significant unique position, a plan for making Luxor an open global museum has been set and included with the comprehensive development plan, depending on a study of the Developmental Center of the UN and the extracted data from studies of Egyptian ministries and institutions; in addition to the UN Organization for Education, Science, and Culture (UNISCO) which is a fundamental partner for considering Pharaoh monuments a human heritage. The development plan includes removing violations from the monumental areas and so the close residential areas to Al-Karnak temple, to be replanned and improved from an urban perspective. In order to achieve this target, a huge number of people of Al-Karnak area have been displaced compulsively, as the removal, property disposition, and displacement decisions have reached more than 5.000 resolutions for houses' removal, in addition to tourist companies and bazaars. This development hasn't unfortunately taken into consideration the social dimension for those displaced away from their homes where they lived for more than 100 years, leading to dispersion and dispersion of families which is a symbol for social and family position, besides
\end{abstract}

$$
\text { المجلد التاسع والثلاثون، الجزء الثاني، ديسمبر V Y r r }
$$


removing shops and bazaars which means destroying of economic income of those people.

The current study drives at identifying the reasons of displacement of people in Al-Karnak and Al-Gorna areas in Luxor governorate; identifying as well the social and physical problems accompanying this displacement. The study's purpose also is to identify the changes occurred because of displacement in social relationships. The study sample consists of (197) items from Al-Karnak and Al-Gorna. Results indicate that compulsive displacement leads to weakness of relative and social relationships causing social dispersion which reflects also on all society and creates social and personal stress in coping with new circumstances requiring more time to cope with the new social, cultural, or psychological conditions. The study recommends making a whole comprehensive evaluation before starting any displacement operations and assuming this occurs for the purpose of development. Evaluation should include impacts of displacement and discovering alternatives and strategies. The study recommends the necessity for participating and sympathizing with displaced people and explains to them the reasons for this displacement and the alternative solutions; in addition to make them participate in planning for displacement operation. Moreover, the authorities in charge should present alternative houses for people and compensate them for the damages. Displacement should not be violent and they should avoid compulsory displacement for the negative social, psychological, and economic effects it leaves on citizens. 